UNIVERSITA' DEGLI STUDI DI TRENTO - DIPARTIMENTO DI ECONOMIA

\title{
A Social Contract Account for CSR as Extended Model of Corporate Governance (Part I): Rational Bargaining and Justification
}

Lorenzo Sacconi 
The Discussion Paper series provides a means for circulating preliminary research results by staff of or visitors to the Department. Its purpose is to stimulate discussion prior to the publication of papers.

Requests for copies of Discussion Papers and address changes should be sent to:

\author{
Dott. Stefano Comino \\ Dipartimento di Economia \\ Università degli Studi \\ Via Inama 5 \\ 38100 TRENTO ITALY
}




\title{
A Social Contract ACCOUnt For CSR as EXTENDED MODEL OF CORPORATE GOVERNANCE (PART I): RATIONAL BARGAINING AND JUSTIFICATION \\ by \\ Lorenzo Sacconi \\ Department of Economics, University of Trento \\ and \\ EconomEtica, Interuniversity centre of research, Bicocca University, Milano \\ lorenzo.sacconi@economia.unitn.it
}

\begin{abstract}
This paper is the first part of a two parts essay aimed at giving a contractarian foundation to the concept of Corporate Social Responsibility (CSR) meant as an extended model of corporate governance of the firm. I fist present the heuristics of the scientific program meant to theorizing over an institution like a system of corporate governance, which is partitioned in two domains, the justification domain and the compliance domain. Bargaining theory, reputation game and reciprocity theories, as distinct pieces of game theory, are the main theoretical tools employed in developing the answer to the relevant questions in the two domains respectively. The first part focuses over justification according to the contractarian point of view. At start, a definition of CSR as an extended model of corporate governance, based on the fiduciary duties owed to all the firm's stakeholders, is given. Then, by setting the basic context of incompleteness of contracts and abuse of authority, I analyze how the extended view of corporate governance directly arises form within the criticism of contemporary neo-institutional economic theory of the firm. Hence, from an application of the theory of bargaining games, the structure of a multistakeholder firm based on the constitutional contract theory is deduced, which satisfies the basic requirements of a justification in the contractarian approach. This is a sequential model of constitutional choice, where at the first step a constitution is chosen and then a postconstitutional coalition game is played. Both the games are solved in terms of the proper cooperative bargaining and coalition game solution concept, and results are interpreted not only according to the perspective of the theory of rational bargaining, but also as an impartial solution, starting form a fair status quo and corresponding to reasonable intuitions on distributive justice. On these basis the query for a prescriptive theory of governance and strategic management - able to overcome the criticism raised against the lack of determination and unicity of a multi-stakeholder model of corporate governance and strategy - is answered, so that I am able to define an objective function for the firm consistent with the idea of CSR as a model of governance. At last, the paper tells the contractarian story, which can be taken as a potential explanation of the firm, of how the multi-fiduciary corporation may emerge from the first and the second social contract, as a firm endowed with the typical structure of control, but constrained by CSR obligations that those who in the firm hold a position of authority owe to all the non controlling stakeholders.
\end{abstract}

Key Words: Corporate Social Responsibly, Fiduciary duties, Stakeholder theory, Theory of the firm, Incompleteness of contracts, Social contract, Bargaining games, Nash bargaining solution, Distributive Justice, Impartiality. 


\section{Introduction and motivations (parts I and II)}

This essay aims at giving a contractarian foundation to the concept of Corporate Social Responsibility (CSR hereafter) meant as an extended model of corporate governance of the firm. In order to account for an institutional model of corporate governance the idea of rational agreement (i.e. the social contract) must work simultaneously in two directions: on one hand it must work as a justification by giving moral reasons to accept the institution from an impartial and impersonal standpoint; on the other hand, the same idea must show direct implication to personal incentives and motivations to implement in practice the institution. In fact within a "state of nature" situation, namely a situation of pre-institutional strategic interaction, the institution can be implemented only if the agreement is self-enforceable. In other words, the social contract can resort to no other source of implementation than those the agreement is able to induce by itself. David Gauthier made clear this point by distinguishing two separate rationality tests that the theory of "morals by agreement" needs satisfy simultaneously (see. Gauthier, 1986, pp.116-118) ${ }^{1}$ :

a) Internal rationality: it is a rationality appraisal that all individuals would accomplish when faced with the decision of entering any agreement over rules enabling to escape a reciprocally unprofitable "natural interaction" and to start a mode of mutually beneficial cooperative interaction. It asks for an ex ante condition of rationality concerning how to reach the agreement over one point out of the set of possible bargaining outcomes. "Internal" is typically the rationality of accepting a deal in a bargaining game over a set of possible outcomes each coinciding with a distribution of a cooperative surplus and construable as behaving according to the prescription of a given institution. Thus, it is "internal" because it understands rationality from within the perspective of bargaining - which takes for granted that if an agreement is reached, then it will be carried out for the mutual advantage of the bargainers. Internal rationality (or ex ante rationality) indeed has one single problem to solve. Rational bargaining takes place in situations where there is some feasible surplus to be distributed amongst the individual participants granted that they are able to reach an agreement. But there are too many agreement possible - some preferred by one party others preferred by another. Hence, to devise a solution acceptable to all implies solving a mixed motives game of coordination. A bargaining game is a way to solve this coordination problem before playing the cooperative game in which the agreed joint strategy will be carried out in order to produce and allocate the surplus. Thus, the ex ante problem of selecting by bargaining a unique solution can be detached form the ex post problem of implementing the contract itself. As far as we are in the internal rationality perspective, we have only to deal with the problem of ex ante acceptability of an agreement. To be sure, this does not exclude that the agreement itself can be seen as involving apparently different questions, couched in the languages of "mutual personal advantage" and "distributive justice and fairness". Which bargain would be accepted by each player from her self-interested standpoint? What agreement would

\footnotetext{
${ }^{1}$ Even though Gauthier's technical solution to the problem of external rationality, constrained maximisation, has not gained large acceptance, nor I will pursue it here, his heuristics for the programme of a rational-choice-based theory of the social contract remains according to me unrivalled.
} 
be acceptable form an impartial and impersonal standpoint? Would the agreement players will accept be also "fair" according to our best intuition of just distribution of the cooperation outcome? All these related questions have to be answered in the ex ante perspective.

b) External rationality: when we move form ex ante to ex post perspective, we ask whether any agreement may have been agreed can also be complied with by the same players who agreed on it. This is a different problem because the game-logic of compliance is different from that of entering a bargain in a cooperative game. It is instead the logic of an ex post non cooperative game, in which players decide separately but interdependently whether or not to comply with the ex ante agreed contract. Under this perspective the question is not so much whether the contract provides reasonably high joint benefits and distributes them in an acceptable fair way, but mainly whether there are incentives to cheat on the counterparty in the agreement given the expectation that he abides by the contract. Thus the search for external rationality must confront, according to Gauthier, with the problem of potential divorce between individual rationality (expected personal utility maximisation) and social optimality (i.e. Pareto efficiency), which is instantiated by the typical Prisoner's dilemma game.

Ken Binmore made also a similar point in his series of contributions to "game theory and the social contract" $\left(1989,1991,1994\right.$ and 1997) ${ }^{2}$. These authors - notwithstanding their strong differences - put the program of giving a satisfactory contractarian foundation to institutions in both the terms of cooperative bargaining theory on one hand, and non-cooperative game theory on the other hand, and here, and also elsewhere (see Sacconi 1991 and 2000), I follow this mode of theorizing. However there are more aspects than the mere game theoretical ones to be discussed in this account of CSR as corporate governance model. Just to outline the set of problems I will be dealing with

\footnotetext{
${ }^{2}$ In criticizing both Harsanyi and Rawls for their use of individual decision theory in modelling social justice - Binmore (1989) argues that an ex ante social contract under the "veil of ignorance", i.e. reached from an impersonal and impartial standpoint, should be better modelled as a (at least two players) bargaining over the intersection of the outcomes spaces of two typical cooperative Nash bargaining problems, generated by the symmetric permutation of the axes representing the players' utility assessment with respect to a given outcomes space. This is the case just because this symmetric space of outcomes can also be interpreted in a completely different way form the ex post perspective concerning the underlying "game of life". Actually, the ex post rationality of the social contract - when players are back from the hypothetical position to the real game of life - is checked through a non-cooperative-game analysis of the underlying situation aimed to verify whether the social contract (struck under a "veil of ignorance") coincides with a Nash equilibrium of a non-cooperative game. Binmore models the underlying "game of life" as an evolutionary repeated game whose combinations of evolutionary stable strategies coincides with the set of Nash equilibria identifiable in the static game representing the situation in which the social contract has to be put in practice (see Binmore 1997). Moreover the intersection of outcomes spaces resulting form the symmetric permutation of players' places in the cooperative bargaining game defined under veil of ignorance coincides with the set of equilibrium points derivable form the repeated game of life. Thus, were the social contract agreed over one of these points, it would also be stable ex post in so far as it coincides with a Nash equilibrium. Then the bargaining model devised for the ex ante agreement can be appreciated not just as a way to reach an impartial outcome within the symmetric bargaining game, but also as a way to select an equilibrium amongst the many possible in the underlying game of life. The clue to this theory is its simultaneous accounting for two separated rationality requirements to the social contract, quite akin to the internal and external rationality tests outlined in the main text.
} 
along this essay, let me partition them into two large categories that echoes the distinction made just before.

A) First, I define the context of justification for a business ethics norm as the domain in which the condition of validity of a norm (to say, a business ethics code of conduct or a CSR-code of corporate governance) coincides with its impartial rational acceptability. Thanks to impartial acceptability it gains its normative force, i.e. prescribes action or behaviour to the agents. The contractarian approach rests on the hypothesis that a rational agreement model is the best way to account for justification, and the one I will pursue here will also understand the idea of a rational agreement in terms of an outcome of a bargaining game appropriately defined. In this context the questions that will concern us are four:

(A1) Can we develop a bargaining model whereby an institutional framework for CSR as corporate governance is deducible as the solution for the players' rational calculation of their best bargaining strategy? This question concerns the ex ante or "internal" rationality of a model of governance seen as an outcome of a social contract amongst stakeholders: it asks whether the CSR model of governance could be acceptable for each and whichever stakeholder once he takes the role of a rational bargainers in a hypothetical situation defined as the "social contract" position. The idea is that if each player will recognise that it is individually rational to him and also to whichever participant to agree upon such a possible outcome of the bargaining game, then we have provided a justification at least in the sense of rational mutual advantage;

(A2) Rational mutual advantage as the basis for accepting a deal from each and whichever individual player's standpoint in a bargaining game, however, is not all that matters in the context of justification. Acceptability may also require a second kind of test concerning the moral features (not only the bargaining-game ones) of the deal the parties would have struck through hypothetical bargaining, and these concern both the notion of impartiality and that of fairness. To check for the first, it must be verified that the bargaining rational solution is invariant under the permutation amongst the point of views of all the participants in the hypothetical bargaining situation. But also freedom from any moral arbitrariness, like the influence of force, fraud and manipulation has to be checked. Moreover the bargain must also be free from lock-in effects, which are the inherent source of unfairness in re-contracting situations usually taken as the starting point for the contractarian explanation of why the firm as "transaction governance structure" emerges. Moreover we can still check for the fairness of a social contract, even though agreed in a morally depurated bargaining situation, in terms of its correspondence to our best moral intuitions of what should be a fair or equitable distribution of cooperative benefits amongst the firm's stakeholders. Quite obviously singling out acceptable principles of distributive justice for the balancing amongst the stakeholders' claims will result in a basic feature of the contractarian theory of the firm. In fact, the equitable balance would transmit justice to the corresponding structure of fiduciary duties owed by the firm to all its stakeholders and to the CSR governance structure as a whole.

(A3) But if distributive justice principles are singled out through rational bargaining over governance structures of the firm, this can also provide for somehow precise definitions of the fiduciary duties that makes the same idea of CSR and multistakeholder firm less undefined and vague. This can answer the third question to be 
asked, which concerns the actual prescriptivism of a stakeholder's normative theory. In order to be actually prescriptive it cannot be confined only to some very loose ethical standards that most institutional arrangements of the firm may satisfy, leaving the governance structure and the management strategy underdetermined. It should also prescribe a management strategy or a stringent set of constraints whereby a strategy can be singled out.

Indeed, one of the most serious drawbacks in the existing social contract theories in business ethics is that they are not able to derive definite prescriptions for the institutional structure of the firm and for the business ethics norms that would be accepted via a social contract by the stakeholders of the firm. The indefiniteness of local social contracts over the specific business ethics norms regulating specific business community, groups, firms or organisations in Donaldson and Dunfee's ISCT (1994, $1995,1999)$ is paramount to this weakness. ${ }^{3}$ They see this indefiniteness as a force of their approach because of their interpretation of the notion of morally-free zone. But as a matter of fact we cannot derive form that theory any contractarian explanation of how local business norms, for example concerning the self-regulation of a large business corporation, would be shaped by a social contract amongst the firm's stakeholders. Starting from the assumption of "bounded moral rationality" to allow such indefiniteness in local social contracts (which is replicated also at the global social contract level, as in ISCT we cannot find any contractarian deduction of hyper-norms which should constraint the freedom of agreeing on whatever specific norm at local level) misses the point. In fact, general abstract principles of ethics, seen as the result of both the hypothetical social contracts at the global and at the local level (i.e. at the firm level), should be seen as an alternative approach to rationality with respect to the utility maximising model of rationality. The latter is based on the implicit assumption that the decision maker is able to represent mentally all the logically possible states of affairs and every possible decision consequence and calculating the utility maximum over these possibly infinite spaces of states and consequences. The former instead is based on abstract and general principles of ethics which are a remedy to the inevitable cognitive limitation of the consequentialist model of economic rationality. They in fact admit - by typically fallible but nevertheless reasonable default reasoning - the formation of expectations over conducts that take place in the presence of unforeseen states of the world - those states that we cannot predict because of our bounded cognitive capabilities. Due to incompleteness of contracts and bounded rationality, economic institutions allocate through property rights and hierarchical organizations decision rights to certain parties in any sub-set of the economy. The need for general and abstract ethics principle (both at global and local levels) rises from the risk this discretion may be abused. Thus bounded rationality cannot be a reason to put aside the search for an ex ante procedure able to single out general and abstract principles of ethics (the social contract), for this would leave us without any defence against the risk that allocated discretion is abused. ${ }^{4}$ At least this drawback must be recognised as what allows the critics - for example Michael Jensen (2001) - to condemn the stakeholder

\footnotetext{
${ }^{3}$ Paramount to this indeterminacy is also the Kantian theory (and hence in some sense contractarian) of the firm put forward by Norman Bowie (1999) in so far as it attempts no more than defining some generic standards but remains unwilling to single out the governance structure of the firm according to the Kantian view.

${ }^{4}$ This was in fact the main motivation of my previous book on the social contract of the firm (Sacconi 2000)
} 
approach for its inability to provide a clear benchmark against which management strategies and company performances can be assessed, being this indeterminacy also the basis for the charge of opening the route to opportunistic behaviour on the part of managers.

(A4) All the foregoing problems concern the need of a well devised normative model. They could be better answered in the event that the contractarian approach were able to tell a story about the emergence of the firm, whereby the stakeholders agree on a determinate constitution of the firm, defining legitimate claims of those in a position to run the firm but also of those in a position of being subjected to the authority of the former. This story would be a potential explanation of how the stakeholders could have built up the firm by striking a balance and collectively deciding the priority order in which different interests have to be met and pursued as the goal of the company. Thus, the last question to be asked is whether the contractarian account can also give a "potential explanation" of the emergence of the firm. Of course it should be told in a language that makes it comparable to other explanations about why and how the firm emerges as an economic institution (typically explanations told in the field of economic theory of the firm)

Let me step now to the second large category of problems.

B) By the context of compliance and implementation is meant the domain where the validity of a business ethics norm is to be appraised in terms of its effectiveness, i.e. its capability to induce endogenous motivations or incentives causing behaviour conforming to the norm, so that the norm results implemented in the agents behaviour.

Justifications by themselves do not answer questions about the implementation of a CSR normative model of corporate governance, for the agent's standpoint in the justification context is neutral, i.e. detached from the particular personal perspective of each concrete agent (let be the individual or an artificial actor like the firm or a board of directors). In the implementation context instead reasons for action are agent-relative (Nagel 1986). They meet intentions, motivational drives and preferences which the agent holds simply because he is that particular agent in that particular decision position. This simple condition of realism suggests that effectiveness of a norm must be seen as the requirement that by implementing the norms the agent will also pursue his preference in a rational manner (in the sense of coherence amongst preferences and between preferences and actions), admitting both the view that complying can be a tool for fulfilling preferences (instrumental view) and that the norm itself may influence preference formation (intrinsic view).

Taking a contractarian standpoint in the justificatory domain, of course, simplifies a lot also the accomplishment of the implementation task. Impartiality within a contractarian framework in fact amounts to no more than a condition of invariant individual rational acceptance of a given bargaining outcome (under the permutation of personal standpoints allowing the impartial decision-maker to take in turn each players' point of view). Thus impartiality is no more than invariance in a class of agent-relative reasons for action.

Nevertheless relevant part of the task remains to be accomplished. Implementation is the typical sphere where non-cooperative games are relevant and ex post rationality is required, whereas invariance of the individual decisions to accept a norm dictating a joint strategy to all the players concerns ex ante rationality only. In the implementation 
stage instead separate but interdependent strategies are under consideration, and the players are always enabled to say either they want to implement the conjoint strategy or not. It follows that the main problem to be solved in the implementation context is how a CSR norm undertaken voluntarily can also generate motivational causal forces strong enough to induce the execution of the norm in situations where it may require the agent a counter-interested behaviour at least in the immediate. Clearly this would be the case for corporate directors, managers or proprietors were a CSR model of governance to require - as it will likely require - to share the firm's rent or surplus with other stakeholders.

In the lasting debate over the relationship between rationality and morality some has tried a reform of instrumental rationality to include within it also rational choice over dispositions to choose ${ }^{5}$. A disposition would constrain later choices so that the agent will be able to disregard local incentives even if these imply that there are local advantages in deviating form the action plan corresponding to the disposition. Given that the disposition allows abiding by a plan disregarding local incentives to deviate from the plan itself, it can be shown that having the disposition corresponding to a plan of conditional cooperation is beneficial. It actually allows the decision maker to gain higher overall utility when she meets (and recognizes) another decision maker symmetrically disposed, whereas her utility equates that of a non disposed agent when such a non disposed agent is met (and recognized). This being true for all, any rational actor should decide by instrumental rationality calculation to undertake the disposition letting him abide by a plan of conditional cooperation, which allows also locally counter-interested actions.

I will not follow these lines of reasoning, however. These reforms of instrumental rationality seem in fact to presuppose what they should demonstrate. Whereas these approaches are expected to reduce morality to rationality by showing that abiding by a moral norm is rational, on the contrary they must presume that moral dispositions are out there endowed with all their disciplining force independent of rational choice. And whereas dispositions must be understood as choices at our disposal - something we can decide either developing or not - they are also presumed to command our later behaviours, being immune form opportunistic changes when they seem fit, as if these choices were out of our control.

The most natural answer concerning compatibility between compliance to a norm (for example a norm of CSR in the management of the firm) and the rational pursuing of personal preferences therefore remains reputation. Reputation- seen as a mean for personal advantage - is an incentive in so far as it is instrumental to trust relationships among the firm and its stakeholders, which are conductive to better and low-cost transactions fulfilling preferences. Conformity to a norm, which per se is not conductive to personal interest, turns out to be in the agent's best interest because it affects reputation and this affords mutually beneficial transactions. Answering the question about effectiveness of a norm thus implies a careful consideration of the conditions under which the reputation mechanism can properly work. Thus I partition the problems to be faced within the implementation domain into two subclasses concerning how reputation effects can be effective in the field of business ethics.

\footnotetext{
${ }^{5}$ It is the case of Gauthier's constrained maximisation theory $(1986,1990,1996)$ and McClennen's resolute choice theory $(1990,1993)$.
} 
B1) The cognitive problem. Economic agents are endowed with bounded rationality and hence the supposition that reputation may depend on commitments defined conditionally over any possible state of the world is unrealistic. Reputation can become obstructed if the firm does not know how to make itself recognisable or against what benchmark to allow appraisal of his honest behaviour when unforeseen contingencies emerge such that traditional commitments are mute over them. Here is the place where the cognitive role of explicit even though voluntary business ethics norms, like as a code of ethics or a CSR management standard, enters the picture. From the implementation standpoint, answering the question about the cognitive role of explicit business ethics norms within the reputation mechanism replies also to the lack of prescriptivism and unicity criticism (see again Jensen 2001): it would be no more true that a bounded rational manager can resort but to "shareholders' value maximisation" because of the simplicity of the rule. Following a CSR governance and management standard may be much more consistent whit Simon's view of procedural rationality.

B2) The motivation problem. Once the cognitive problem is solved, reputation will activate incentives to comply with a voluntary norm prescribing the CSR model of corporate governance. Till now no exception is needed to the standard model of selfish economic man. However reputations can be of many kinds. A company endowed with relevant market power and inducing idiosyncratic relationships with its stakeholders, could develop the reputation of abusing the trust of its employees, costumers, suppliers, capital lenders just as much as it is needed to leave them nearly indifferent between staying and staying out the relation with the firm itself. Then a company by giving just a bit to the stakeholders, can attempt to acquire their acquiescence to its substantive incompliance. This is not the case in practice, however. Stakeholders, or at least those who practice stakeholders' activism, declines acquiescence and actively counteracts corporate hypocritical conduct. How does the social contract approach account for these apparently irrational and unselfish actions? Recent behavioural theories of the economic agent's motivational complexity suggest interesting explanations, as they variously concentrates on intrinsic value, social preferences and iniquity aversion, reciprocity and intentional kindness. ${ }^{6}$ In this essay, however, I will resort to a related but original view of deontological motivations as it is strictly connected to the idea that motivations are driven by coherence with a principle or ideal. It is indeed a contractarian view of conformist preferences and reciprocity in that non selfish utilities derive from the desire to conform to an ideal of fairness, granted that the ideal can be drawn from a hypothetical contract and the other participants in the social contract are also expected to reciprocate conformity to the same ideal of fairness.

This essay is split in two parts. Sec. 2 of part I gives my basic definition of CSR as an extended model of corporate governance. Sec. 3 discusses how an extended view of corporate governance arises form within the criticism of contemporary neo-institutional economic theory of the firm, and sets out the basic context of incompleteness of contracts and abuse of authority that any attempt to justify and implement the model

\footnotetext{
${ }^{6}$ Among the studies suggesting to go beyond the mere selfish representation of human preferences the following can be remembered Bernheim (1994), Rabin (1993), Chareness and Rabin (2002), Sugden (1998), Frey (1997), Falck amd Fishbaker (2000), Fehr and Schmidt (2001), Falk, Fehr and Fishbaker (2003). However I will refer in this essay to my own contributions to the field (see Sacconi 2004, Grimalda and Sacconi 2002, 2004, Sacconi and Grimalda 2004). For these references see the bibliography at the end of part II.
} 
must fit in. Sec. 4 develops in detail the deduction of the structure of a multi-stakeholder firm based on the constitutional contract theory, which satisfies the basic requirements put forward in points $\mathrm{A} 1$ and $\mathrm{A} 2$ of this introduction. This quite long section is the normative core of the essay and is couched with the minimum necessary use of the tools of bargaining games. I apologize if the use of these tools is nevertheless cumbersome to the non technical reader, but using less game theory would have made the formulation of any consistent and precise notion of rational bargain impossible. Hence in sec. 5 the query for a prescriptive theory of governance and strategic management - question A3- is answered so that I am able to define an objective function for the firm consistent with the idea of CSR as a model of governance. Sec. 6 finally tells the contractarian story asked for in point A4, which can be taken as a potential explanation of the firm emergence.

Part II (see the related paper "A social contract account for CSR as extended model of corporate governance (Part II): compliance, reputation and reciprocity" infra) starkly changes the picture, as I exit there the domain of justification to enter the implementation and compliance domain. In section 1 of part II I discuss at long the game theoretical problem of compliance and implementation of an ex ante agreed contract. In sec. 2 I introduce the model of reputation games with reference to the basic game of trust, which is the second technical piece of game theory that is needed to make sense of all this discussion about implementation, compliance and self-regulation. This is necessary to understand in particular why self-regulation meant as the mere resort to a long-run strategy in a repeated game of trust fails in making sure the reputation of the firm when the game is surrounded by incomplete contracts and unforeseen contingencies. This is so for the cognitive fragilities of the reputation mechanism and the impact of unforeseen contingencies over them. Sec. 3 elaborates upon the idea of proper self-regulation based on explicit norms, and develops the logic and the structure that these self-regulatory norms must satisfy if they have to serve as a gap-filling tool for the remedy of cognitive limitations in the reputation mechanism. This section, in answering the question raised in point B1, echoes my previous book on the social contract of the firm (Sacconi 2000), where the logical foundations for the reputation mechanism based on an ethical decision procedure employing fuzzy logic and default reasoning are worked out. Here I give only the intuitions. At last, sec. 4 of part II develops an entirely new application of the theory of conformist preferences to the problem of the motivational role that is played by business ethics norms in activating stakeholders' activism. This section answers the "real life" question raised in point B2 of this introduction. The price to be paid is the more formalised language of this section. In fact it was impossible to take conformist preferences as known and moreover the very result derives straightforwardly from the calculation of stakeholders' overall utilities when the hypotheses of conformism and reciprocity are introduced.

\section{A definition of CSR as a model of extended corporate governance}

Let me start by suggesting a definition of CSR: Corporate Social Responsibility is a model of extended corporate governance whereby that runs a firm (entrepreneurs, directors, and managers) have responsibilities that range from fulfilment of their fiduciary duties towards the owners to fulfilment of analogous fiduciary duties towards all the firm's stakeholders. 
This definition is consistent with propositions that can be found in official documents delivered by international organisations ${ }^{7}$. For example the EU states:

"By stating their social responsibility and voluntarily taking on commitments which go beyond common regulatory and conventional requirements, which they would have to respect in any case, companies endeavour to raise the standards of social development, environmental protection and respect of fundamental rights and embrace an open governance, reconciling interests of various stakeholders in an overall approach of quality and sustainability" (Promoting a European Framework for Corporate Social Responsibility, European Commission, Green Paper, p.4, Brussels, 18.7.2001, emphasis added).

This quotation shows that the UE Commission regards CSR as a form of corporate strategic management and as a system for the governance of transactions and relations between the firm and its stakeholders. It is clear that here 'governance' is no longer the set of rules simply allocating property rights and defining the owners' control over the management of a firm. Instead it resembles the neo-institutional view whereby the firm, like the contract and other institutional forms, is a 'governance system' which establishes diverse rights and obligations in order to reduce 'transaction costs' and the negative externalities of transactions. Moreover the definition is consistent with some of the promises delivered by the first attempts to develop a normative stakeholder theory. For example, Freeman and Evan recognise the fiduciary relationships amongst the firm and all its stakeholders and the ensuing nature of the firm as a tool for coordinating efforts aimed to the satisfaction of all the stakeholders' interests. Therefore they ask for (but unfortunately do not develop in detail) a definition of corporate governance and strategy based on Kantian principles like the one that, being every stakeholder not only a mean for the firm but also an end in herself, her rights and interests should be pursued by the firm and she should also participate in the decision processes affecting her interests (see Even and Freeman 1989, p.82). Similarly, Donaldson and Preston, in concluding their famous essay on the priority of the normative side of stakeholder theory, stated that a managerial stakeholder approach should derive from a complex view of property rights, including not only claims to control and residual earning, but also the owner's constraints and responsibilities toward stakeholders (see Donaldson and Preston 1995, pp.83-85).

To make precise my definition however let me define its basic terms:

a) Fiduciary duties. It is assumed that a subject has a legitimate interest but is unable to make the relevant decisions, in the sense that s/he does not know what goals to pursue, what alternative to choose, or how to deploy his/her resources in order to satisfy his/her interest. S/he, the trustor, therefore delegates decisions to a trustee empowered to choose actions and goals. The trustee may thus use the trustor's resources and select the appropriate course of action. For a fiduciary relationship - this being the basis of the trustee's authority vis-à-vis the trustor - to arise, the latter must possess a claim (right) towards the former. In other words, the trustee directs actions and uses the resources made over to him/her so that results are obtained which satisfy (to the best extent possible) the trustor's interests. These claims (i.e. the trustor's rights) impose fiduciary duties on the agent who is entitled with authority (the trustee), which s/he is obliged to fulfil. The fiduciary relation applies in a wide variety of instances: tutor/minor and

\footnotetext{
${ }^{7}$ see also OECD, Principles of Corporate Governance, chapter 3, April, 1999.
} 
teacher/pupil relationships, and (in the corporate domain) the relation between the board of a trust and its beneficiaries, or according to the predominant opinion, between the board of directors of a joint-stock company and its shareholders and then more generally between management and owners (if the latter do not run the enterprise themselves). By the term 'fiduciary duty', therefore, is meant the duty (or responsibility) to exercise authority for the good of those who have granted that authority and are therefore subject to it. ${ }^{8}$

b) Stakeholders. This term denotes individuals or groups with a major stake in the running of the firm and who are able to influence it significantly (Freeman and McVea 2002). However, a distinction should be drawn between the following two categories:

(i) Stakeholders in the strict sense: those who have an interest at stake because they have made specific investments in the firm (in the form of human capital, financial capital, social capital or trust, physical or environmental capital, or for the development of dedicated technologies, etc.) - that is, investments which may significantly increase the total value generated by the firm (net of the costs sustained for that purpose) and which are made specifically in relation to that firm (and not in any other) so that their value is idiosyncratically related to the completion of the transactions carried out by or in relation to that firm. These stakeholders are reciprocally dependent on the firm because they influence its value but at the same time - given the specificity of their investment - depend largely upon it for satisfaction of their well-being prospects (lock-in effect).

(ii) Stakeholders in the broad sense: those individuals or groups whose interest is involved because they undergo the 'external effects', positive or negative, of the transactions performed by the firm, even if they do not directly participate in the transaction, so that they do not contribute to, nor directly receive value from the firm.

It is evident that these two categories cannot be sharply separated. For example, a manufacturer in a developing country who supplies a component for an industrial good assembled in a Western country is essentially dependent on his contract; and with his low labour costs (due to the customer's market power) he makes a crucial contribution to the Western firm's profits. At the same time, however, if a mature technology is used, he is easily replaceable by the Western firm, whose dependence on the supplier is therefore limited (in short, the reciprocal dependence relation is not symmetric).

We are now able to appreciate the scope of CSR defined as an extended form of governance: it extends the concept of fiduciary duty from a mono-stakeholder setting (where the sole stakeholder relevant to identification of fiduciary duties is the owner of the firm) to a multi-stakeholder one in which the firm owes fiduciary duties to all its stakeholders (the owners included). It is obvious that classification of stakeholders on the basis of the nature of their relationship with the firm must be regarded as important in gauging these further fiduciary duties. ${ }^{9}$

\footnotetext{
${ }^{8}$ On fiduciary duties see Flannigan (1989).

${ }^{9}$ At first sight, it might be objected that many stakeholders, in both the 'strict' and 'broad' senses, do not have relations with a firm such that they formally delegate authority to those who run it (for example, they do not vote), with the consequence that the fiduciary duties as defined earlier do not apply to them. However, in the model of the social contract as a hypothetical explanation of the origin of the firm - see section 6 - all the stakeholders participate in the "firm's second social contract", with the consequence that their trust constitutes the authority of the firm's owner and manager. This also explains how the
} 


\section{Economic theory and the idea of extended fiduciary duties}

\subsection{Theory of the firm.}

Let me now inquire whether economic theory provides support for the thesis that the firm has 'extended' responsibilities towards its stakeholders. According to neoinstitutional theory (Williamson 1975, 1986; Grossman and Hart 1986; Hart and Moore 1990; Hart 1995; Hansmann 1996), the firm emerges as an institutional form of 'unified transactions governance' intended to remedy imperfections in the contracts that regulate exchange relations among subjects endowed with diverse assets (capital, labour, instrumental goods, consumption decisions, and so on). These assets, if used jointly, are able to generate a surplus over the cost of their use that is higher than in the case of their separate use by each asset-holder. However, contracts by which these asset-holders regulate their exchanges are incomplete: they do not include provisos covering unforeseen events, owing to the costs of drafting them, or because the cognitive limits of the human mind make it impossible to predict all possible states of the world. Yet for these assets to be used in the best manner possible, specific investments must be made: investments undertaken with a view to the value that they may produce within an idiosyncratic contractual relation. This entails that the surplus generated with respect to the costs sustained by each party to the exchange is determined by the undertaking of specific activities with specific counterparts (suppliers, customers, employees, financiers, etc.). Let us assume that parties behave opportunistically (that is, they are egoists who act with astuteness). Thus, once the investments have been made, contractual incompleteness means that the terms of the contract can be renegotiated, so that the party in a stronger ex post position is able to appropriate the entire surplus, thereby expropriating the other stakeholders. But if agents expect to be expropriated, they will have no incentive to undertake their investments at the optimal level. This expectation of unfair treatment gives rise to a loss of efficiency at the social level.

The firm responds to this problem by bringing the various transactions under control of a hierarchical authority - the authority, that is, of the party which owns the firm and through ownership is entitled to make decisions over the contingencies that were not ex ante contractible. Unified governance supplements incomplete contracts with authority relations through the vertical and horizontal integration of the units that previously made separate contributions. The firm is therefore a special contractual form: when contracts lack provisos contingent upon unforeseen events, they can be 'completed' with the 'residual right of control' which entitles its holder to decide what should be done about decisions not ex ante contractible- that is, decisions 'left over' from the original contract and that become available only when unforeseen situations occur.

The residual right of control underpins authority: those parties entitled with residual right of control may threaten the other parties to the contract with exclusion from the physical assets of the firm, thereby ensuring that ex ante non-contracted decisions are taken ex post to their own advantage. They are thus safeguarded against opportunism by the other stakeholders, and they are able to protect the expected value of their

authority of the latter may be accepted by these subjects. Moreover, the hypothetical social contract is typically used to explain how authority - that is, legitimate power - may come about at both the political and organizational levels: see Green (1990) and Raz (1985). For a discussion of managerial authority see McMahon (1989) and Sacconi (1991). 
investments in situations where contract incompleteness provides margins of discretion when residual decisions have to be taken. There is therefore an efficiency rationale for the idea of the firm as 'unified governance' of transactions: if one party (a class of stakeholders) has made a specific investment of greater importance than those made by the others at risk, or if its exercise of 'unified governance' discourages opportunism by the others to appropriate the surplus, then that party should be granted the property right and with it the right to take 'residual' decisions. This is also the basis for regulation of authority delegation from the owners to directors or managers by corporate governance rules, when the owners themselves are not able of directly exercising the entire residual right of control. Fiduciary duties owed to the owners must guarantee that delegated exercise of residual rights of control by the board of directors or managers will maintain or improve the efficiency of their original allocation to the selected class of stakeholders.

\subsection{The risk of abuse of authority.}

However, one should not underestimate the risks of the firm qua unified governance. There is not just one single stakeholder at risk because of contract incompleteness; it is usually the case that multiple stakeholders undertake specific investments (investments in human capital, investments of trust by consumers, investments of financial capital, investments by suppliers in raw materials, technologies and instrumental goods). Contracts with these stakeholders are also incomplete.

Yet if a firm brings its contracts with certain stakeholders (labour contracts, obligations towards and relations with minority shareholders) under the authority of a party to whom is allocated control over residual decisions (for example, the controlling shareholder group) - and more generally if a party is enabled by its de facto power to exercise discretion over ex ante non-contractible decisions concerning implicit or explicit contractual relations with the other stakeholders (consumers, customers, suppliers, creditors, etc.) - what, one may ask, is there to ensure protection of investments and interests other than those of the controlling stakeholder? It is evident that if fiduciary duties attach only to ownership, those stakeholders without residual right of control will not be protected by the fiduciary duties of those who run the firm.

The inherent risk, therefore, is an abuse of authority (Sacconi 1997, 2000). Those wielding authority may use it to expropriate the specific investments of others by exploiting 'gaps' in contracts - which persist even under unified governance (in fact it simply allocates to only one stakeholder the right to 'fill' those gaps with its discretionary decisions). Those in a position of authority, in fact, are able to threaten the other stakeholders with exclusion from access to physical assets of the firm, or from the benefits of the contract, to the point that those other stakeholders become indifferent between accepting the expropriation and forgoing the value of their investments by withdrawing from the relation. Thus the entire surplus, included that part of it imputable to efforts and investments made by the non controlling stakeholders, will be appropriated by the controlling party. Again forward-looking stakeholders will be deterred form entering the hierarchical transaction with the controlling party. In general, this will produce an internal crisis of legitimacy between firm and stakeholders (a crisis in the relationships between the organizational authorities and participants in the organization) and an external crisis of trust (in relationships with stakeholders that have entered into contractual or external relations with the organization). Various 
stakeholders will ex ante have a reduced incentive to invest (if they foresee the risk of abuse), while ex post they will resort to conflicting or disloyal behaviour (typically possible when asymmetry of information is inherent in the execution of some subordinate activity) in the belief that they are being subjected to abuse of authority. In the economist's jargon, this is a 'second best' state of affairs (less than optimum): all governance solutions based on the allocation of property rights to a single party may approximate social efficiency, but they can never fully achieve it. This much is acknowledged by the theoreticians of contractual incompleteness when they point out that the allocation of the residual right of control induces the party protected by that right to over-invest, while those not so protected are induced to under-invest, with a consequent shortfall with regard to the social optimum (Grossman and Hart 1986; Hart 1995).

On the other hand, if the stakeholder category entitled to exercise ownership (the double right of controlling residual decisions and claiming residual revenue; see Hansmann $1987,1996)$ is selected on the basis of its ability to minimize total costs deriving form the summation of contractual costs borne by of various stakeholders and costs of exercising authority, it is by no means certain that a solution will be found which reduces each of those costs to the minimum (that is, reduces opportunism suffered by each stakeholder to the minimum). Sufficient for this solution to emerge is, for example, that the governance costs of one class (the capital-holders, for example) are low enough to counterbalance a relative increase in the contractual costs borne by another class (the workers, for example) compared to alternative cases (for instance the case in which there is no centralized governance, or the one in which it is a sub-set of workers that governs, or the consumers). In this case, too, some incentives are nullified, which distances the real-world solution from complete (Pareto) social efficiency. The fact is that the relative (in)efficiency depends on manifest or simply expected unfairness: separation between efficiency and fairness (a myth of neoclassical economics) is no longer feasible when we face the real-life problem of working out acceptable solution for the governance of transactions.

My suggestion is therefore that when CSR is viewed as 'extended governance', it completes the firm as an institution of transactions governance (Sacconi 2000). The firm's legitimacy deficit (whatever category of stakeholders is placed in control of it) is remedied if the residual control right is accompanied by further fiduciary duties towards the subjects at risk of abuse of authority and deprived of the residual control right. At the same time, this is a move towards greater social efficiency because it reduces the disincentives and social costs generated by the abuse of authority. From this perspective, 'extended governance' should comprise:

- the residual control right (ownership) allocated to the stakeholder with the largest investments at risk and with relatively low governance costs, as well as the right to delegate authority to professional directors and management;

- the fiduciary duties of those who effectively run the firm (administrators and managers) towards the owners, given that these have delegated control to them;

- the fiduciary duties of those in a position of authority in the firm (the owner or the managers) towards the non-controlling stakeholders: the obligation, that is, to run the firm in a manner such that these stakeholders are not deprived of their fair 
shares of the surplus produced from their specific investments, and that they are not subject to negative externalities. ${ }^{10}$

\section{A theory of the hypothetical constitutional contract of the firm}

This section outlines the theory of the constitutional contract of the firm (see also Sacconi 2000) as the basis not only for the allocation of control over the firm - that is the right to take discretionary decisions and appropriate the surplus - but also to include in this structure other rights - essentially responsibility claims in defence of stakeholders other those protected by the property right. The resulting institutional structure defines the principles of the firm's governance structure consistently with the notion of CSR as a governance model with multiple fiduciary duties.

The model of constitutional contract of the firm rests on an analogy between the social contract theories used to justify "by agreement" both the 'legal constitution' (Buchanan 1979) and the mutually advantageous rules of morals (Gauthier 1986) of a large society on one side, and the economic theory of efficient choice of the control structure of firms, based on the idea of contractual incompleteness on the other side (Williamson 1975, Grossman and Hart 1986, Hart and Moore 1990). An essentially similar feature of these theories in particular is the sequential structure of both models, whereby a 'constitution of rights' is initially established and then, in the next phase, the parties bargain within the institutional structure selected in the light of the occurrence of events which the constitution is unable to regulate in every detail. These events explain why contractual decisions are taken in the second period that have not been taken in the first, but which are nevertheless influenced by the choice set made available to the parties by the rights granted to them by the institutional structure selected in the initial phase. The theory of the firm expresses this situation with the concept of the incomplete

10 I have proposed in previous works (see Sacconi 1991) a social contract view of the firm's ownership and managerial ethics based on a similar re-examination of the theory of firm, as well as the notion of extended fiduciary duties (see also Sacconi 1999, 2000). The cooperative-game-theory of the firm put forward by Mashairo Aoki (Aoki 1984) can be taken as the path breaking work in this theorizing over the firm. By intervening in a discussion about the stakeholder approach to company law (see also Chapman 1993, Machey e Miller 1993, Daniels 1993, Romano 1993), Oliver Hart himself recognized that the risk that non controlling stakeholders may be subjected to contracting costs by those who own the firm would justify some corporate statutes to extend fiduciary duties also to the stakeholders at risk (Hart 1993). Thereafter a convergence to a similar model comes from the merger of the incomplete contract model and the Alchian and Demestz's team production theory of the firm. Hence the firm can be seen as a 'nexus' of specific investments regulated by incomplete contracts and a governance structure, rather than as a nexus of complete contracts, (Zingales 1998, Rajan and Zingales 2000). Based on a similar view, which combines different theories of the firm, is the model of multi-stakeholder governance developed by Margaret Blair and Lynn Stout, which sees the purpose of corporate governance structures as being prevention of opportunistic behaviour among the members of the team that make specific investments. When applied to a public company, this model translates into a board of directors acting as a mediating hierarchy: an authority system charged with the task of finding out the appropriate balance in the protection of diverse interests (see Blair and Stout 1999). The (controversial) legal basis for this form of "impartial governance" exercised by the board of directors and by management in the US joint-stock company is the 'business judgment doctrine': the manager's use of a standard of professional conduct which insulates his/her choices against claims by shareholders (see Blair, Stout 1999, but also see Meese 2002). Similarly moving from a view of the firm as stakeholders' productive team (Kaufman 2002), the board of directors has been seen as a governance structure representing the point of view of all those stakeholders who a) contribute to creating value; b) undertake non diversifiable risks; c) hold strategic information (Kaufman, Englander andWood 2003). 
contracting' due to unforeseen events not contractible in detail ex ante in the initial contract. The idea of contract incompleteness is also implicit in constitutional contractarianism, which envisages that the constitutional agreement pre-selects a restriction on the possible alternatives, allocating the rights and authority used in postconstitutional agreements just because it is not foreseeable in the fundamental contract every action conditional on every state of the world. The theory of the firm associates authority with the allocation of property rights and I follow it under this respect. But I also stress that authority (and therefore ownership) are legitimate only to the extent that they are accepted in the constitutional contract by all the involved parties (the stakeholders). Hence the theory of the constitutional contract of the firm is essentially an application of the ethical theory of social contract to the problem of choosing the structure of rights and obligations that presides over governance of the firm. This includes selecting the party to whom is to be allocated control over the firm, but also (as we shall see) goes beyond ownership and control, to include rights to compensation (or redress) which give distinctive content to the idea of CSR.

\subsection{Rational bargaining over the firm constitutions}

Assume that an economy consists of $\mathrm{N}$ individuals and that $\mathrm{S}$ of them (the stakeholders in the firm) are engaged in a joint productive activity (in various roles: employees, investors and capital lenders, consumers, suppliers of row materials, instrumental goods and technologies, and communities hosting an activity in a given geographical area). These $\mathrm{S}$ individuals constitute a coalition (for simplicity's sake also called $\mathrm{S}$ ) whose characteristic function is super-additive: that is, by acting cooperatively they are able to produce a surplus which would not be forthcoming if they acted separately. Of these individuals, $M$ make specific investments, or they are 'indispensable' for specific investments to yield a surplus. The other members of $S$ instead undertake unspecific actions or supply unspecific assets which add value to the coalition $S$, but they are not strictly locked-in to the coalition in order to realize the value of their investment. Coalition S, as here defined, is coextensive to the concept of team as understood in the theory of the firm. Accordingly, ownership of the firm, as the team of S member, and authority over it, should be allocated among the $\mathrm{M}$ members of $\mathrm{S}$. The other members of $S$ are stakeholders tied to $S$ by relations of varying degrees of intensity. The remaining $\mathrm{N}-\mathrm{S}$ individuals are indifferent to the activity in question (they are not stakeholders in the sense given to the term by the theory).

The model depicts a two steps collective decision-making situation among potential members of the coalition S. ${ }^{11}$ The main collective decisions are taken at the beginning and the third period, while in the intermediate periods individual decisions and information gathering occur. At time $\mathrm{t}=0$ the allocation of rights is decided (rights not only of ownership and control but also of redress and compensation) which determines the structure of control over the productive coalition $S$ through a constitutional agreement. At time $t=1$ the right-holding individuals undertake investment decisions with view to subsequent transactions and joint activities in the coalition. At time $t=2$ events occur which are not covered by a clause in the initial contract. At time $t=3 \mathrm{a}$ new bargaining game begins, defined for each allocation of rights and for every set of investment decisions. That is, the members of the coalition $\mathrm{S}$ negotiate a joint plan of

\footnotetext{
${ }^{11}$ Here I elaborate on an model given by Horace Brock $(1978,1979)$ that also suggests the idea of two bargaining games in sequence, each endowed with its proper solution concept.
} 
action and a distribution of the surplus which reflects investments and events in $t=2$. This problem of sequential collective decision-making is modelled as a compounded bargaining game $\mathrm{Gc}$ on the constitutional and post-constitutional decision, whose first phase is the bargaining game carried out at time $t=0$, when chosen for each player is a set of strategies by means of which a subsequent game can be played at time $t=3$. Note that this set of strategies is a subset of the strategies available in the initial game.

In the background to the constitutional choice game there is a 'state of nature game' to which the players will be back if they fail to agree cooperatively on a constitution. The underlying 'state of nature game' admits a single solution mutually disadvantageous for all parties, namely a sub-optimal equilibrium. In the theory-of-firm-model the 'state of nature' corresponds to the situation occurring at time $t=3$ where contracts were to be renegotiated without any protection, so that the parties would undergo the reciprocal opportunistic behaviour made possible by the incompleteness of the initial contract. Players anticipate this uncomfortable result at the starting phase of the constitutional choice as the 'status quo' that would result in absence of any constitutional framework. Then analytically, the constitutional choice game Gc has as its admissible outcomes the resumption of the 'state of nature' actual result, but also all the other possible outcomes in the 'state of nature', and all the (linear) combinations among those outcomes. In other words, the technological frontier available to the parties has not changed, but now, following agreements, the institutional arrangement make it possible actually to obtain all the outcomes that were previously only virtually possible, and also all the combinations among them. This, therefore, is to assume that whilst in the 'state of nature' the only rationally achievable outcome is the sub-optimal equilibrium $d^{*}$, in the situation of constitutional choice the parties may, on the basis of binding agreements, choose joint strategies that yield them all the outcomes that were only virtual in the 'state of nature', not rationally achievable, plus all their probabilistic combinations admitted by the fact that upon agreement they parties may decide to undertake two or more plans according to which events occur with an agreed joint probability.

It is obviously needed to explain how binding agreements are made possible by moving from the state-of-nature game to the constitutional choice game. The explanation is that the former is a non-cooperative game, of 'prisoner's dilemma' type, with a single but sub-optimal solution, whilst the latter Gc is a cooperative bargaining game, where, if an agreement is reached on a joint plan of action, it is certain that this plan will be implemented. Of course, there is no reason to believe that opting for a constitution rather than for concrete contracts is in itself sufficient to make agreements binding. Thus the explanation is simply that the constitutional choice game is a hypothetical (ethical) normative model in which the parties intend to 'justify' their choice of the constitution and believe that they can act on the basis of what they deem to be right. Given that they are counterfactually considering a hypothetical state of the world in which they are simply seeking a solution agreeable to all parties, one may also hypothesise that they presume themselves able to keep to the agreements reached if these have been negotiated rationally (this too is an acceptable hypothesis for an hypothetical justificatory model). Obviously in the implementation context, as distinct from the justificatory one, it will be necessary to demonstrate that the agreements reached in the hypothetical model of constitutional choice are also backed by effective motivations and incentives for individuals endowed with bounded rationality (which amounts to consider the compliance problem addressed in part II). 
The distinctive feature of the constitutional choice game Gc is that the players (potential members of S) do not have to choose one particular joint strategy. Rather, they simply have to choose a subset of the set of admissible joint strategies (that is, a restriction over each player's set of strategies). Each subset of the strategies of the game Gc defines a limitation on the freedom of action that the players are endowed with in the state of nature'. Thus the choice of any whatever subset of possible strategies coincides with the choice of a 'constitution'. Moreover, each subset of the joint strategies (constitution) in its turn defines a cooperative sub-game, whose admissible outcomes cover only a portion of the outcomes admissible in Gc. This is a coalition game in which the players negotiate on how much they can obtain from cooperation according to their importance for the production of surplus (investments) and according to the constitutional rights that entitle them to take decisions that may influence the final value of cooperation with the others. These games correspond to the bargaining phase that, according to the economic theory of the firm, takes place at time $t=3$ after investments have been undertaken and after unforeseen events unaccounted for by the constitutional contract have occurred, but in which cooperation is now protected by a constitution of rights. That the agreement concluded at time $t=3$ belongs to the possible joint strategies of the sub-game chosen at $t=0$, indicates how the constitution influences the outcomes of the second bargaining phase, restricting the number of strategies latterly available to the players.

The individuals who are candidates for coalition $\mathrm{S}$ therefore take part in a sequential game. I may assume that they resolve the game by starting with the admissible outcomes of the post-constitutional phase and working backwards to the constitutional choice (backwards induction). Consequently, all the admissible outcomes and the solutions of the post-constitutional sub-games can be anticipated before the constitutional choice has been taken. This important simplification can be made in analogy to the theory of incomplete contracts (Grossman and Hart 1986, Hart and Moore 1990, Hart 1995, Tirole 1999), with the caveat that in the real world of bounded rationality and effectively incomplete contracts, the parties will counterfactually reconstruct the ex post situation in the light of the constitutional contract they would have agreed upon in the hypothesis of being been able ex ante to foresee the ex post situations. They therefore will apply the abstract principle of a fair contract according to the information available at that point in time, and will verify ex post whether it has been applied amid the contingencies which have arisen in the meantime (the 'implementation technology' of the social contract model in real-world situations of bounded rationality also asks to be considered in part II on compliance and selfregulation).

With this caveat I therefore assume that, in the second stage, payoffs are assigned according to the solution for coalitional cooperative games known as the Shapley value and whereby each player obtains the expected payoff of the summation over all the possible of the sub-coalitions of $\mathrm{S}$ of the difference among the value when he is the last to enter and when he does not participate, multiplied by the probability that the subcoalitions will form. Given hypothetically each sub-game, the possible levels of investment, and the relative decisions permitted by rights, the players calculate the payoff assigned to them by the Shapley value for the bargaining game that follows every given level of investments. They therefore choose the level of investment that enables them to obtain the highest payoff, on the hypothesis that the others too will 
choose the level of investment at which they obtain the highest payoff. Thus for every post-constitutional sub-game there exists a univocal solution in terms of a precisely defined set of payoffs.

Moving backwards to the initial phase of the constitutional choice, the question arises as to how this phase is handled. Each player knows that the choice of a subset of strategies (a constitution) gives rise to a particular solution for the associated sub-game. The space of the admissible outcomes of the constitutional choice may therefore be regarded as the set of the solutions of all the logically possible post-constitutional sub-games. Consequently, the Gc game too can be treated as a cooperative bargaining game in which the players must agree upon a particular outcome selected within an admissible outcomes space (each point belonging to it corresponds to the solution of an alternative post-constitutional game). The constitutional choice must be made unanimously by all the potential members of S. In fact, the only rational agreement is the one that involves all the members of the large coalition $\mathrm{S}$, for if this agreement is not reached they will fail in their attempt to establish a constitution, and they are doomed to play the 'state of nature' with its sub-optimal solution $\mathrm{d}^{*}$. Point $\mathrm{d}^{*}$ is therefore the status quo of the Gc bargaining game. Consequently, the constitutional choice game is the typical cooperative bargaining game in which by unanimous agreement an efficient solution must be chosen from among all possible ones (set of Pareto outcomes), given the minimum condition that each acceptable agreement must give the parties at least what they would obtain in the status quo $\mathrm{d}^{*}$.

\subsection{Nash bargaining solution}

The most accredited solution for bargaining problems of this kind is Nash bargaining solution: that is, the point on the efficient frontier of the admissible outcome space where the product among the players' utilities is maximum net of the value to them of the status quo (Nash 1950). The solution follows from very general postulates demonstrated to be coincident with various other formulations of the rationality criteria for bargaining processes among Bayesian rational players (Harsanyi 1977, Binmore and Dasgupta 1987). Suffice it to say that if the space of the bargaining outcomes net of the status quo is symmetrical - that is, it includes for each player exactly all the payoffs that can be obtained from the other players - then the solution, which lies on the efficient outcomes frontier, must itself be symmetrical. It must, that is to say, distribute the utility gains with respect to the status quo (the surplus) in equal parts among the bargaining parties. (Under certain conditions of invariance of the solution (i) to changes in the units of measure of the players' utilities, (ii) to changes in the payoff space which eliminate irrelevant bargaining alternatives, and (iii) to symmetric permutations of players' place with respect to a symmetrical payoff spaces, one concludes that the only solution compatible with the postulates is maximization of the Nash product).

Specifically, let me consider a case with two players, 1 and 2, and let us assume that the solution is a point in space $\mathrm{R}^{2}$ enclosed between the positive Cartesian axes U1 and U2, each of which measures the utility for a player of the outcomes of the cooperative game (see Figure 1 for this example). The space therefore represents the outcomes subject to bargaining in terms of their value in utility for the players (i.e. their payoffs). The standard analytical assumption is that the payoff space is convex and compact. The payoff space $\mathbf{P}$ therefore has an efficient frontier (in the upper-right positive region of the Cartesian plan) which represents the set of outcomes for which the players' utilities 
cannot be increased by an alternative agreement without reducing the utility of at least one other player. Below this frontier are agreements with respect to which gains are still possible for all; above it are outcomes unfeasible by any agreement or joint plan of action. All points in the space represent different possible values of the coalition among the two players. In fact, only when all of them agree on the solution of the game can they leave the status quo d, which is represented by a point interior to the space, so that they may benefit form cooperation. The characteristic function of the coalition among all the players is therefore super-additive (it is better to agree than not to agree). Obviously, of interest are only those agreements for which there is an efficient allocation.

But in what point among those on the frontier should the agreement fall? The Nash bargaining solution states that the players will agree on the joint strategy corresponding to the point over the frontier where the maximum product of the individual surpluses holds, i.e. $\operatorname{Max} \Pi_{\mathrm{i}}\left(\mathrm{U}_{\mathrm{i}}-\mathrm{d}_{\mathrm{i}}\right) \quad(\mathrm{i}=1,2$ denotes the various participants in the bargaining), where $U_{i}$ is the utility of the generic stakeholder $i$ for the cooperative transaction that it undertakes with the firm, and $d_{i}$ is the cost of the specific investments made by $i$ in order to participate in the joint action plan (that is, $i$ always at least recoups the cost of its specific investment). The solution assumes that bargaining should provide each player with at least a net advantage, which is the difference between the share of the surplus received and the status quo value. As a consequence of additional rationality postulates, these net individual advantages can be identified as such that the product of all of them is the maximum among those in the set of the possible outcomes of the cooperation. We may say that this is the collective choice function adopted by the members of the coalition, in light of their bargaining, to resolve the problem of their joint action. Notice that the ratio in which the shares of the surplus a1/a2 are distributed is proportional to the ratio between the marginal variations in the players' utilities $\partial \mathrm{U} 1 / \partial \mathrm{U} 2=-\mathrm{a} 1 / \mathrm{a} 2$. On the basis of Nash's postulates (1950) and those of the ZeuthenHarsanyi (see Harsanyi 1977), this solution expresses a bargaining equilibrium based on individual rationality of the players

In the constitutional choice-bargaining game this solution has to be found out within a symmetrical outcome space generated, as said, from all the virtual outcomes of the 'state of nature', which represent all the logically possible subsets of the set of strategies of the constitutional choice game - so that all the points in this space can also be interpreted as solutions for possible post-constitutional games. The Nash bargaining solution of the constitutional choice game therefore corresponds to a constitution on the basis of which a particular post-constitutional game begins once the admissible strategies have been selected and that will distribute to the players equal parts of the cooperative surplus calculated with respect to the constitutional choice outcome space (in the units of measurement of each player). This constitution obviously distributes the set of rights - among the right to ownership and governance within the firm (coalition S) - so that no party has an advantageous bargaining position when the postconstitutional bargaining takes place. 
U1

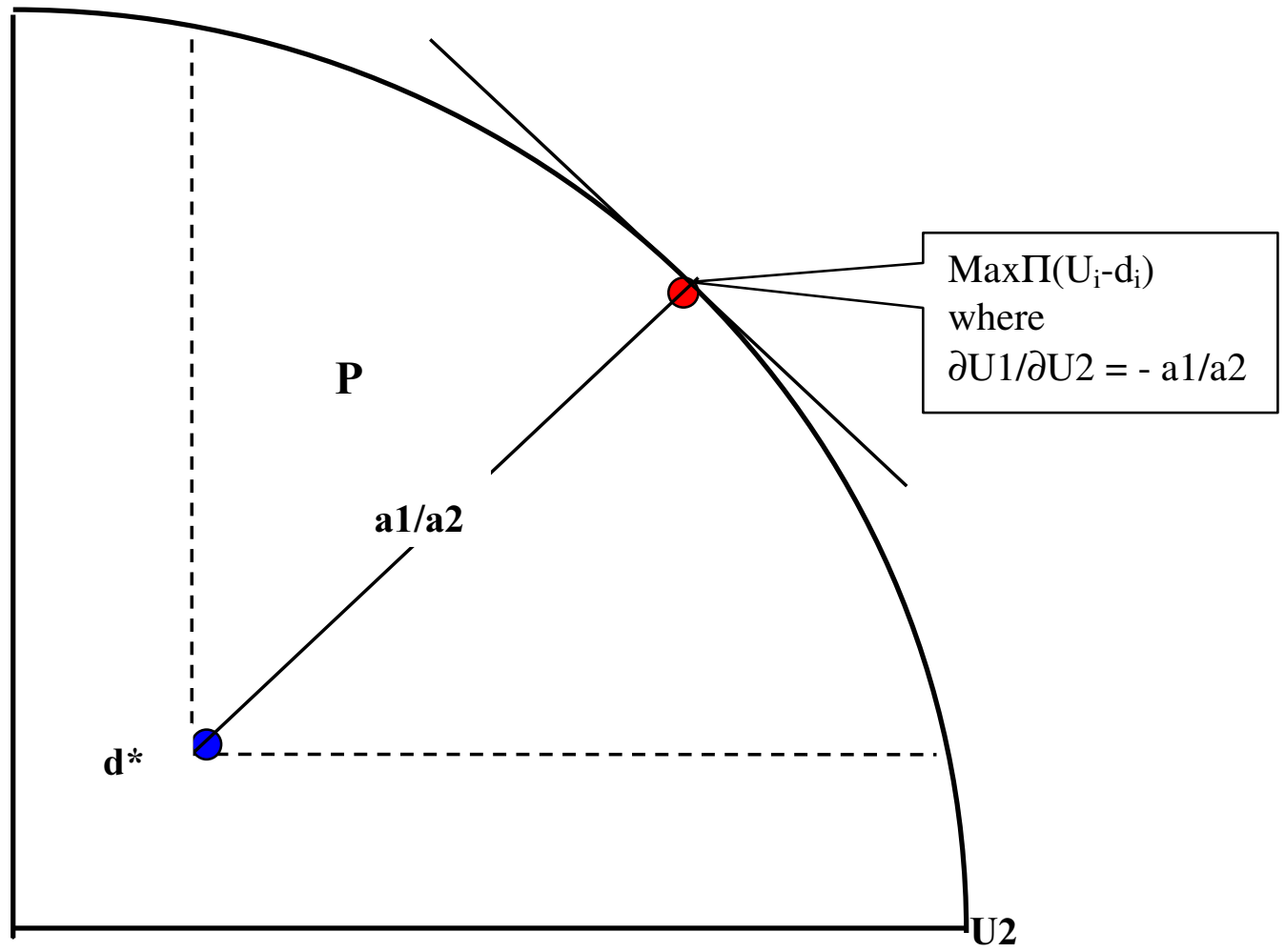

(Fig. 1. A symmetrical two players cooperative bargaining game and its Nash solution)

\subsection{Rational contracting and distributive justice}

What interpretation can we give to the solution of the game $G_{C}$ in terms of the theory of distributive justice?

a) Rational bargaining as impartiality. Rational bargaining comprises an elementary notion of impartiality of choice, given that not only do all the parties rationally accept the solution (which is therefore equally rational for them all) but the solution is anonymous: in fact, the Nash product remains unchanged under symmetrical permutation of place among the players. If the players change their place with respect to the set of strategies and the utilities associated with them, so that all the results that player A could previously obtain are now achievable by player B, and vice versa, then the solution will offer to player A exactly what it previously offered to player B (and vice versa). Hence the solution is anonymous and not attached to the name or personal identity of the player. In particular, if the payoff space is symmetrical, when the players change place with respect the strategies and outcomes, the solution will not change: it is, that is to say, exactly the same point in the space and the same cooperation pattern with permuted roles. This means that the only relevant features are the possibilities to contribute to the cooperation and their evaluation in terms of the participants' utility. Let me assume the standpoint of an impartial observer who wants to find a collective solution which impartially reflects these features (and which is therefore acceptable to all). If I examine the bargaining problem from all the individual points of view, assuming the position of each participant in bargaining in turn, then I reach the conclusion that each of them accepts a solution which is identical with those accepted by all the others: the Nash bargaining solution. In other words, the Nash solution is the 
solution that the observer would come by reasoning from the point of view of any whatever participant.

b) Moralized status quo. The impartiality of bargaining is obviously limited by the fact that it is affected by the status quo: that is, what the parties could have obtained in any case without cooperation will be conserved by the bargaining solution. This is a fundamental tenet of bargaining: why would the parties be interested in adhering to the agreement if they can obtain greater utility by staying out of it? The fact remains, however, that the surplus to be distributed in the payoff space is calculated on the basis of the status quo. Consequently, the better the status quo for a participant, the higher the payoff from bargaining. But if the status quo reflects 'force' or 'fraud', these morally arbitrary features will be preserved by the bargaining solution. But consider the actual relevance of this classic objection (Rawls, Sen and Brian Barry, for example, have made it in various ways). The hypothetical social contract expresses a model for the choice of social institutions which are antecedent to any form of social interaction that will be responsible in turn - for example via the social division of labour - for costs and benefits allocated amongst the participants in social interaction. It is therefore clear that no form of social injustice can be represented in the status quo. What remain to be eliminated consequently is the arbitrariness due to the reciprocal use natural force and fraud in the 'state of nature'. ${ }^{12}$ This difficulty is avoided by conventionally setting at zero-level the status quo for each party. All the effects of the destructive natural interaction among the parties must be neutralized if each of them is to agree to play the game of justifying by agreement the social institution. Zero-setting the status quo for all parties has another important property: no player at the outset of the constitutional bargaining game will have already borne the costs of the specific investments which ex post (at time $\mathrm{t}=3$ ) may induce him to acquiesce to unequal payoffs in order to recover at least those costs. By contrast, the status quo which is taken as given when the constitutional solution is chosen ensures to each player at least the payoff that he had before bearing the costs of the investment (which are instead reflected in the costs/benefits balance associated to each joint strategy). Given that in the constitutional choice I select a post-constitutional game with a specified final allocation of payoffs, the constitutional choice will never be subject to the lock-in effect that characterized the renegotiation of contracts in the theory of the firm.

c) Correspondence to intuitive principles of justice. The sequential bargaining game solution can be given an ethical interpretation not only because of the neutrality of rational bargaining but also on the basis of the correspondence between each of the two concepts of solution I have employed and the intuitive principle of justice respectively appropriate to the bargaining phase in question. The solution to each post-constitutional game according to the Shapley value can be interpreted as an application of the principle of remuneration on the basis of relative contribution. The Shapley value is in fact the linear combination (weighted with equal probability assigned to all the coalitions with the same number of members) of the marginal contributions that an individual can make to all the coalitions. On the other hand, the Nash bargaining solution - provided the units of measure for the individual utilities are assumed to be interpersonally calibrated (which is not required for simple calculation of the Nash bargaining solution)

\footnotetext{
${ }^{12}$ Gauthier (1986) discusses the idea of "Lockean proviso" as a moralisation for the bargaining status quo; my point differs slightly in that I want to introduce in the players' legitimate pre-bargaining claims also to coverage of costs of any specific investment
} 
- can be interpreted as an equivalent solution to the distribution proportional to relative needs, that is, proportional to the relative intensity of variation in preference for the players at the point where the solution falls. This is the consequence of what has been shown in section 4.2, where I said that the ratio in which the shares of the surplus are distributed is proportional to the ratio between the marginal variations in the players' utilities $\partial \mathrm{U} 1 / \partial \mathrm{U} 2=-\mathrm{a} 1 / \mathrm{a} 2$. In fact, once the utility units are interpersonally calibrated, so that each unit expresses the same magnitude of preference for both the players, the ratio between their marginal variation measures the players' relative needs (see Brock 1979, Sacconi 1991, 2000).

The twofold ethical characterisation of the bargaining solutions matches the different nature of the problems of collective choice modelled by the post-constitutional games on the one hand, and the constitutional choice game $G_{C}$ on the other. Before they play a post-constitutional sub-game, the parties undertake their specific investments bearing in mind the guarantees offered by the constitution in regard to their possibilities of reaping the benefits of cooperation. Then, in the light of events occurred in the meantime, they calculate the effect of their participation in each coalition (the possible sub-coalitions of $S$ ), and finally contract with $S$ the part due to them for concluding an agreement which will enable $S$ to pursue its best joint strategy with which is associated a super-additive production function (or characteristic function). The solution of each sub-game distributes benefits to which the players have already contributed through their investment decisions and through their decision to join the coalition S. Therefore appropriate at this point is the distribution criterion based on relative contribution or, put it otherwise, relative merits. Instead, in the case of the constitutional bargaining game $\mathrm{G}_{\mathrm{C}}$, none of the parties subscribing the agreement has yet contributed anything, so that the merit or relative contribution criterion does not seem to be a valid criterion of distributive justice here. Chosen in $\mathrm{G}_{C}$ is the constitution on the basis of which the investment decisions will be taken. Rather, what the various players will be willing to contribute depends on the choice of the constitution. It is therefore obvious that account must be taken of the need to provide efficient incentives for their contribution. Also these rights-for-incentive, however, must be accepted in an agreement among participants in the constitutional bargaining who consider only what is relevant from their current point of view. In the absence of any relevance of their merits, in this case only needs can be accounted for. Hence an appropriate criterion for solution will refer to the relative needs of the parties for what will subsequently enable them to contribute to the cooperative production.

To conclude, the solution to the game of constitutional choice consists of the following rule for constitutional choice:

(i) select a socially Pareto efficient constitution calculated on the basis of the particular status quo $(0, \ldots, 0)$ which

(ii) distributes the surplus generated by the cooperation among the members of $\mathrm{S}$ in proportion to their relative needs, if the distribution is seen in the context of the constitutional choice (with respect to the payoffs space $P$ of the $G_{C}$ constitutional choice),

(iii) but also proportionally to the relative contributions, if seen in the context of the post-constitutional choice which occurs in the coalition sub-game which begins after the constitution has been chosen 


\subsection{Exclusive property rights and the duty to compensate the non controlling parties}

We have thus far considered the more abstract case in which every logically possible constitution is subject to constitutional choice. In other words, every logically possible subset of admissible outcomes in $\mathrm{G}_{\mathrm{C}}$ corresponds to a constitution than can be chosen. In this case, every point in the payoff space of the constitutional choice game corresponds to a solution of an admissible constitution (subset of strategies). This would be a world in which it is possible to finely partition decision rights in whatever proportion among the parties. In other words, institutions that greatly restrict freedom are just as possible as extremely liberal ones, and likewise institutions which impose every intermediate restrictions or which grant rights to a greater or lesser extent to one or other participant. Given that the choice can be made from such a wide range of options, the achievable institutions would be perfectly efficient and fair, and they would not be subject to the second-best results typical of the theory of the firm.

Instead, I hypothesise more realistically - as suggested by the modern theory of property rights - that only a certain number of restrictions on the set of the strategies of the base Gc game are institutionally feasible. I shall regard as institutionally feasible a constitution under which a relationship of authority can be established and which consequently can ensure that any contracts made between the parties can be enforced and the completion ex post of any gap of ex ante contracts. In particular let us allow that only exclusive allocations of the property rights over the whole of the physical assets of the firm are institutionally feasible. Connected to this is the possibility of assigning all the authority to one party or another, but no intermediate gradations of it (as in the egalitarian solution found previously). Let us therefore assume that the ownership arrangements allowed by the feasible constitutions are such as to bias postconstitutional bargaining heavily in favour of one or other party. Corresponding to these constitutions are particular post-constitutional games whose admissible outcomes all together cover only a portion of the outcome space obtained in $\mathrm{Gc}$ from the original game of the 'state of nature'. The salient aspect of this situation is that the Nash bargaining solution with respect to the all-inclusive payoff space of the $G_{C}$ game may now not coincide with the solution of any of the institutionally feasible sub-games, simply because the choice must fall within the set of institutionally feasible solutions, putting aside others as 'Utopian' (even though they are more efficient and fairer).

How should we deal with the constitutional choice in this imperfect world? The criteria proposed by economic theory are based on the importance of investments and on indispensability. If one party when endowed with ownership is able to ensure a higher surplus, he may be able to purchase the property right from the other. If we take as the status quo an arrangement of rights under which one party has ownership, it can be verified that the alternative arrangement of property rights is more efficient if it is possible to find a utility side payment which enables the second party to induce the first to cede to him the property right. That is, ownership is allocated to the party who has more important contributions to make to production, or who is indispensable for the investments of the others to be productive. This implies choosing the feasible postconstitutional sub-game whose solution is closest to the Pareto frontier of the game.

However, the rational consent of the other agents also has to be accounted for in the context of the constitutional bargaining model. They may be ready to accept that the player who makes the most valuable investment or who is most indispensable for 
realising the value of these investments should be given property rights. Nevertheless, making the constitutional choice requires the consent of all the players whose membership in the coalition ensures the super-additivity of the value of $\mathrm{S}$ (whether they make specific investments, are indispensable agents with respect to some assets, or ordinary members of $S$ who add some value to the coalition). This requirement entails that the proceeds of the actions will reward all parties fairly.

Fortunately, I'm still able to calculate the fair distribution that recognizes the legitimate claims of the parties. The initial position is 'without rights', so that the appropriate status quo of an $\mathrm{N}$ person game is therefore $(0, \ldots, 0)$. Contribution-based claims are not relevant here because in $G_{C}$ the contributions have not yet been made. Investments come into play only before the sub-games are played. Distribution according to the criterion of relative need can now be calculated by taking as the set of permissible outcomes the convex hull of all the linear combination of points in the payoff spaces defined by the institutionally feasible games and the status quo $(0, \ldots, 0)$. Within this set of points, the Nash bargaining solution permits isolation of a fair payoff distribution. This solution is clearly different from the constitutional contract in the Utopian context, since in general the combination of the two or more payoff spaces relative to institutionally feasible games (constitutions) $G_{i}$ is only a subset of the payoff space of the constitutional choice game $G_{C}$ and does not necessarily includes all the north-east frontier of the $G_{C}$ payoff space (see fig. 2 for an example with two players: P3 is the convex combination of the payoff space P1 and P2 associated to the feasible constitutions; within it the Nash bargaining solution is Pareto inferior to the same solution relative to the entire payoff space $P$ relative to the basic $G_{C}$ game)

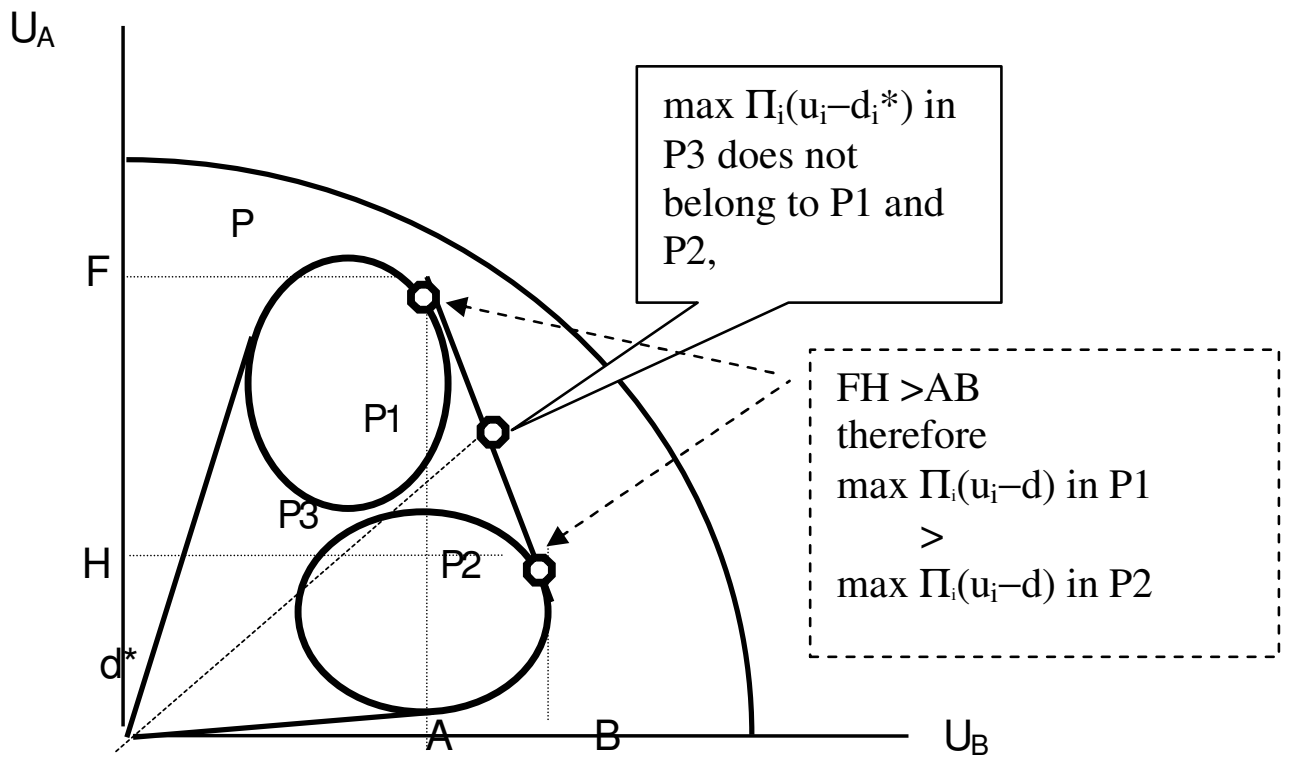

(Fig. 2. P1 and P2 are payoff spaces for the institutionally feasible Constitutions $C 1$ and $C 2$, the solution to $P 3$ is the constitutional contract which can be reached only by a utility side payment).

The problem, however, is that not even one of the solutions of feasible constitutional sub-games corresponds to this distribution (with two post-constitutional games, the fair solution is a linear combination of their two solutions, that is, a 'mid-way' between 
them not belonging to any space of the two feasible game). The solution that can be suggested is based on a side utility payment. In order to get from the status quo $(0, \ldots, 0)$ to the most efficient solution of a particular sub-game, the player who would obtain a position of advantage must underwrite a side utility payment. On conclusion of this payment, the distributions of payoffs will conform to the criterion of distribution proportional to relative need, despite the fact that with this particular arrangement of property rights he is able to obtain a larger portion of the surplus than the other parties. Consequently, the remuneration of those that do not have ownership takes the form of compensation for ceding their quotas of freedom By way of example (see again fig.2), consider the case of two players. If $\mathrm{A}$ is more efficient (because his investment is more important), this means that there is one feasible constitution $\mathrm{C} 1$, which assigns ownership to $A$, which defines a sub-game $G_{1}$ with a payoff space $P_{1}$ whose solution is more efficient than that of the alternative constitution $\mathrm{C} 2$ which assigns the property to $B$ and which defines a sub-game $G_{2}$ with payoff space $P_{2}$. Thus, for reasons of incentive, ownership must be given to A. However, in order to obtain ownership A must still take account of B's claims and compensate him. The constitutional contract stipulates that the fair distribution must correspond to the point in which the two members of the cooperative coalition will be remunerated in proportion to their relative needs. This solution is calculated within the payoff space $\mathrm{P}_{3}$ generated as the convex hull of the linear combinations of the outcomes associated with the actually feasible constitutions. This requires utility side payments by which the party who makes the most efficient use of ownership compensates those are less efficient until the cooperative surplus is distributed according to the criterion of relative need. The idea of compensation obviously requires the firm's institutional structure to incorporate a notion of 'social responsibility', by which is meant the obligation of the party allocated ownership to compensate the other parties to the social contract for the advantage that he has acquired by being granted authority over the firm. The social responsibility of the party with authority over the firm is measured by its ability to run the firm consistently with the principle of having all parties a share in the firm's surplus, as established by the Nash solution of the constitutional choice (in its realistic version). This applies even if, under the outcome resulting immediately from the constitutional sub-game selected, the party with authority has the legal means to appropriate an extra-rent, i.e. a substantially larger part of the surplus. This extra-rent must be reimbursed in accordance with the principle of constitutional choice based on relative needs.

The constitutional contract therefore stipulates the following institutional structure of the firm in the imperfect world of institutionally feasible constitutions:

i. assuming that the N-S members remain indifferent and therefore do not undergo negative external effects from the firm,

ii. the firm constituted by the coalition $S$ will be headed by the party under whose governance the Shapley-value solution distributes to the various stakeholders an aggregate value that is greater than the alternatives;

iii. this governing party will have the right to take residual decisions or delegate them to the management and take the residual on the proviso that

iv. the cooperative surplus made possible by the constitutional arrangement selected is measured from a status quo including 'coverage' of the costs borne by each 
stakeholder in making its specific investment (that is, it is free from the 'lock-in effect),

v. each member of the coalition $\mathrm{S}$ obtains a share of the surplus that reflects its relative contribution to the value of the coalition $S$ in the institutional form selected,

vi. to which must be added (or subtracted) a quota by virtue of which the final distribution is equal to the distribution proportional to relative needs defined in the constitutional phase with respect to the set of institutionally feasible outcomes.

This concludes my deduction of the institutional framework for corporate governance of the socially responsible firm from a normative model of rational bargaining.

\section{An objective-function for the firm}

The main objection brought against CSR is that the multi-stakeholder approach to the firm's governance leaves management without a clearly-stated and uniquely defined 'bottom line', to be used as the benchmark against which to evaluate its success or failure (Jensen 2001). The consequence, the argument runs, is that the management exploits this situation to pursue its personal interests. It comes up with every possible device to conceal its essentially self-dealing behaviour behind the interests of some or other stakeholder. Whereas, the critics of CSR maintain, it is easy to check the managerial strategy (among the alternatives available at any particular time) against the criterion of increasing as much as possible the firm's profits, this is not the case of 'stakeholder value', since this consists of numerous dimensions to maximize simultaneously (the interests of the various stakeholders). Consequently, stakeholder value contains an intrinsic contradiction - the pursuit of conflicting, or at any rate divergent, goals at the same time - so that the choice of which strategy to adopt is ultimately left to the mere managerial discretion. ${ }^{13}$ In sum, this objection amounts to say that the multi-stakeholder approach can not provide the firm a prescriptive guidance as clear as profit maximisation.

It should be clear, however, that this objection does not apply to the model of the social contract of the firm proposed here - which by no means ignores the existence of a distributive conflict, and instead resolves it by identifying a bargaining equilibrium that permits mutual cooperation among the members of the team. Once the firm is understood as a team of participants with specific investments at stake, the metaphor of a 'bargaining cooperative game' among multiple stakeholders can be used. Stakeholders must agree on a shared action plan (a joint strategy) which allocates tasks among the members of the team so that the contribution of each of them is efficient (because it produces the maximum surplus net of each stakeholder's costs). The 'bargaining cooperative game' played by the stakeholders is typically one of mixed interests. Although it is in their common interest to cooperate, because this enables them to produce a surplus that would otherwise be impossible, conflict nevertheless persists among the stakeholders over the distribution of the value created. 'Governance' and strategic management consequently consist in the solution of the problems of identifying the joint strategy that the stakeholders (as the players in the cooperative game) may utilize to coordinate themselves - so that strategic management can reduce

\footnotetext{
${ }^{13}$ This danger is also stressed by Tirole (2001), who however recognizes the relevance of the stakeholder approach to corporate governance.
} 
bargaining costs (time, conflict, etc.) and the costs of gathering information on the alternatives available and on the intentions of each players about cooperation.

As we have seen in the foregoing section, counterpart to the philosophical contractarian model is a mathematical model of rational bargaining. If the bargaining outcome space is well defined and one accepts the Nash's, or Harsanyi-Zeuthen's postulates of bargaining theory, the solution is defined uniquely, so that the set of admissible solutions reduces to one single alternative. Calculable within the outcome space is indeed the Nash bargaining function - the product of the utilities of the various stakeholders with specific investments net of costs for that investments - that is an aggregative function of their utilities. Where the product (the aggregation) is maximum, there is a bargaining equilibrium (i.e. a rational agreement among the participants in the social contract) corresponding to the Nash bargaining solution (Nash 1950; Harsanyi 1977). In any event, various theories of bargaining yield solutions which quite closely resemble each other - see Gauthier (1986), Kalai and Smordinski (1975) and Rubinstein (1987) - as they are slight changes of the basic Nash's solution; and for the purposes of this study, identifying a set of 'close' solutions compatible with the idea of rational bargaining seems good enough.

It is remarkable that the bargaining solution is exactly as computable as the firm's profit function in microeconomic theory. Hence I can simply substitute maximization of the function which assigns the solution to the bargaining game for profit maximization, and assume this as the firm's computable objective-function. This solution is simultaneously an answer to both the problem of cooperation and distributive conflict among the stakeholders. Thus the query for a simultaneous satisfaction of multiple possibly conflicting objectives is answered by the maximisation of a unique solution function defined over the outcome space.

Notice that finding out the bargaining equilibrium does not need operational interpersonal comparisons of utility (which operationally are very problematic) in order to be calculated (interpersonal comparisons can be confined to the interpretive level ${ }^{14}$ ) and thus it is not informatively over-demanding concerning what the manager needs to know about the intensity of stakeholders' preferences. It obeys, in fact, simple axioms of individual rationality in bargaining - like the decision to grant a concession according to the expected personal utility given the probability that the counterparty will accept or refuse it, or that a player will not make a concession that he or she would not expect the counterparty will make in a similar situation - and conditions of mutually expected rationality, like expecting that the willingness of acceptance by the counterparty depends on a symmetric probabilistic assessment of the first party behaviour, and not to expect the counterparty to accept something that oneself would not accept, and so on (see Harsanyi 1977). These postulates includes the invariance of the solution with respect to the choice of the units of measure if individual utilities. Of course, if these postulates are taken literally, they can be criticised as unrealistic; and it is likely that in the real world agents are unable to maximize or to estimate probabilities coherently, or to make accurate forecasts about the rational behaviour of others. But what matters for my purposes so far is that these postulates are a good approximation of rational behaviour in a hypothetical (ideal) bargaining situation among stakeholders and at the same time they provide a prescriptive guidance to strategic management - one no

${ }^{14}$ See Brock (1979), and Sacconi (1991). 
less prescriptive and clear than profit maximization advocated by critics of CSR like Michael Jensen. Of course the point of bounded rationality maintains its force, but I will address it in the second part of this essay, when implementation will come under scrutiny.

\section{The social contract as potential explanation of the firm's emergence}

Thus far, the social contract has been presented as a normative theory by which to identify the terms of an agreement that would be acceptable from both a rational bargaining perspective and an impartial standpoint - that is, from the point of view of any whatever stakeholder. However, social contract theory can also furnish a reconstruction - understood as a 'potential explanation' - of how bargaining may give rise to a firm with both fiduciary duties towards the owners and social responsibility (i.e. further fiduciary duties) towards all the stakeholders.

Consider the 'state of nature' prior to the creation of the firm. Bilateral transactions among stakeholders regulated by incomplete contracts are subject to reciprocal opportunistic behaviour, with the consequence that prohibitive bargaining costs render them inefficient. At the same time, the parties to those transactions are entirely unconcerned about the negative external effects of their transactions on other agents, who although they do not participate, are nevertheless affected. This is a Hobbesian scenario in which the life of economic transactions among agents is "solitary, poor, nasty, brutish, and short". ${ }^{15}$ The stakeholders thus address the problem of creating an association whereby all their transactions can be undertaken in accordance with agreedto rules and are therefore not subject to contract-costs, while at the same time the negative effects on those who do not participate in the benefits from the transactions are reduced to the minimum. The 'First Social Contract' of the firm (pactum unionis) is nothing other than the agreement which the stakeholders reach among themselves to set up this association. They negotiate on the association's constitution, which consists in a common plan of action (joint strategy) to which each of them contributes either by carrying out a positive effort or by simply refraining from applying his/her veto. This first social contract of the firm stipulates as follows:

a. rejection of shared plans of action which generate negative externalities for those not participating in the cooperative venture or, if these negative externalities are essential for the production of the cooperative surplus, a compensation of third parties so that they are rendered neutral;

b. production of the maximum surplus possible (difference between the value of the product for its consumers, who belong to the association, and the costs sustained by each stakeholder to produce it);

c. a distribution of the surplus which is 'fair', or rationally acceptable to each stakeholder in a bargaining process free from force or fraud and based on an equitable status quo, that is, considering the surplus net of the specific investments.

However, if an attempt is made to reach this form of an ideal association (the 'just firm') which eliminates all the participants' contract-costs, they arrive in practice to an organisational form which is found to be inefficient from the point of view of its

${ }^{15}$ See Hobbes, Leviathan, (1651), part 1, chapter 13. 
governance costs. The stakeholders discover, for example, that the general assembly of all members is unable to take coherent decisions in a reasonable amount of time. In the absence of a monitoring system, once the members of the association have established fair shares of the surplus to be distributed among them, they have an incentive to act opportunistically and not to play their part. Coordination problems arise on how the joint strategy can be implemented under changing circumstances, which may alter beliefs and reciprocal expectations asymmetrically. The stakeholders consequently draw up a second social contract of the firm (pactum subjections) ${ }^{16}$ by which they constitute, in the proper sense of the term, a governance structure for the association. It is only now that the association becomes a hierarchical structure.

The second social contract provides that authority should be delegated to the stakeholder most efficient in performing governance functions (the taking of residual decisions, devising coordination solutions as circumstances change, monitoring, the enactment of sanctions, excluding potential free riders, etc.). For this reason, it can also be seen as a contract between the stakeholders and those who is given control over the firm (social contract with the firm). After comparative examination of the governance costs of each stakeholder, the one with the lowest costs is selected and assigned ownership, and is therefore the one to which the right of governing the association is delegated (Hansmann 1996). This class, which is remunerated with the residual is authorised to delegate some discretionary decisions in regard to running the firm to professional director and managers, and to appoint those who are in the authority position of running the firm. Prima facie, their authority will be effectively constituted that is, the delegation will remain valid - as long as they comply with what I call

- Narrow fiduciary proviso: the owners are remunerated with the maximum residual revenue possible (in forms compatible with the diverse nature of the controlling stakeholder: profits, returns, discounts, improved conditions of service, improved conditions of employment, and so on) in the light of conditions obtaining in the firm's specific market.

However, it is evident that this proviso entails that the positions of the other stakeholders change (from the "just firm" to just a firm). Formerly co-equal members of the association, they are now subject in various ways to the discretionary decisions taken by the stakeholder entitled with authority, and by the administrators that it has appointed. Unlike in the standard economic theory of the firm, in the social contract theory the risk of the abuse of authority can squarely be faced. The second social contract is therefore conceived in a manner such that this cost of hierarchy is forestalled as well. Hence, under the second social contract, the stakeholders agree to submit to authority, thereby rendering it effective, if the contract contains the proviso that stipulates that the firm's new governance structure must comply with fiduciary duties towards all the stakeholders (owners and non-owners).

- Extended fiduciary proviso:

(i) Towards the non-owners

\footnotetext{
${ }^{16}$ Interestingly, also Blair and Stout (1999) adopt the analogy between the firm and the two social contracts typical of the social contract tradition.
} 
- The firm must abstain from activities which impose negative external effects on stakeholders not party to transactions, or compensate them so that they remain neutral;

- The firm must remunerate the stakeholders participating in the firm's transactions with pay-offs (monetary or of other kinds, for example in terms of the quantity, quality and prices of goods, services, working conditions, etc.) which, taken for granted a fair status quo, must contain a part tied to the firm's economic performance such to approximate fair/efficient shares of the surplus (assuming that this is positive) as envisaged by the first social contract. ${ }^{17}$

(ii) Towards the owners: The firm must remunerate the owners with the maximum residual compatible with fair remuneration - as defined by the first social contract - of the efficient contributions made by all the other stakeholders.

The telescopic nature of the narrow and extended provisos in the second social contract reflects the sequential structure of the constitutional model developed in sec. 4. Over there the implementation of an ownership structure in the post constitutional phase able to remunerate merits and incentive investments - was compatible with the choice made from the first phase constitutional viewpoint, in which the social contract over institutions is consistent with the criterion of stakeholders' relative needs. Here, on the other hand, the second social contract solves the problem of minimizing governance costs and allocating rent under the constraint of satisfying the first social contact, which concerns the agreement over a constitution of the productive association, or team, and is identified by a cooperative bargaining solution. It consequently must be coherent also with the relative needs distribution principle.

What does this hypothetical explanation yield? It yields a definition of the company goal - that is, the interest that the manager acting in the name of the company must serve - which is consistent with the contractarian model put forward in sec. 4. According to this reconstruction, in fact, the manager (appointed through the second social contract) has a special fiduciary duty towards the owners (or the 'residual claimant') that has delegated authority to him/her (via narrow fiduciary proviso). This duty applies, however, only under the constraint that the general fiduciary duties are fulfilled towards all the stakeholders - which is defined via the extended fiduciary proviso. I may thus construct the corporate interest by means of a hierarchical decisionmaking procedure which moves from the most general conditions to the most specific ones:

- First step: minimize the negative externalities affecting stakeholders in the broad sense (perhaps by paying suitable compensation);

- Second step: identify the agreements compatible with the maximization of the joint surplus and its simultaneous fair distribution, as established by the impartial cooperative agreement among the stakeholders in the strict sense;

\footnotetext{
${ }^{17}$ Note that meant here is remuneration in utility and not necessarily in money. Put in economic parlance, this remuneration consists of the consumer rent, the producer rent, the worker rent and so on, accruing to each of them from the firm's transactions. This means that some stakeholders may not want to receive monetary benefits from the firm, but rather improvements in working conditions or in purchasing power, in the quality of goods and services, of contractual conditions, etc., to which the shares of the surplus are in any case devoted..
} 
- Third step: if more than one option is available in the above defined feasible se, choose the one that maximizes the residual allocated to the owner (for example, the shareholder).

Hence, the narrow corporate interest (the one usually advocated by supporters of the "shareholder value" view) results from a series of steps which select the admissible ways in which this interest can be satisfied - that is, those that are consistent with the various constraints imposed by the first social contract on the owner's behaviour. It should be emphasized that this concept cannot be reduced to that of value maximization for the 'residual claimant' (the owners) once constraints imposed by positive contractual obligations have been fulfilled. This is because I recognize all contracts are incomplete, and they are always susceptible to opportunism (even by those who run the firm), so that it is the entire hierarchical decision procedure which provides the basis for satisfying the corporate interest - i.e. the social contract identifies the goals or the internal (not merely external) moral constraints that channels managerial discretion.

\section{Conclusion}

Normative stakeholder theories have failed in various ways to specify a criterion for striking a balance among a firm's stakeholders. This is due to the fact that they have not adequately addressed the problem from the point of view of designing the institutional governance structure of the firm: that is, the complex set of rights which establishes the legitimate claims (of various kinds) of both the stakeholders with ownership and control and the other stakeholders that in various ways participate in the firm or exchange with it. To do so, they should have neither restricted themselves to the managerial (i.e. micro) level, however essential it may be, nor enlarged too much their scope to include the macro-social contract as a whole. Instead they should have examined the ethical design of the firm as a particular social institution (i.e. at the meso level). ${ }^{18}$ This design must necessarily draw upon the economic and legal models of the firm. The theory of the constitutional contract of the firm offers solutions to these problems. It is better than the alternatives - for example Donaldson and Dunfee (1955) - because it explains how a firm may be created by agreement among the stakeholders, simultaneously considering efficiency and fairness and drawing on a formal model of rational bargaining which enables univocal solutions to be drawn. Accordingly, the firm is an institution that may come into being in relative isolation from other institutions, provided that the social contract protects stakeholders in the broad sense against external effects. It thus makes it possible to propose an institutional arrangement which, without omitting the efficiency requirements typical of the economic and legal analysis of contracts and property rights, entails a substantial reform of the governance structure of the firm in respect to conventional models.

From an economic point of view, the institutional arrangement selected by the constitutional contract of the firm serves the purpose of achieving greater social efficiency. The investment decisions of each agent, in fact, will be made with a view to compensation and redress, to which incentives will adjust as a consequence. That is, the owner will not over-invest in order to appropriate extra-rent, while the parties under his authority will not under-invest due to the risk of being expropriated. From the legal point of view, it furnishes a definition of the multiple fiduciary duties of the board of

18 This point as been made also in a valuable critical paper by Hendry (2001) 
directors (and a fortiori of the owners) of the firm towards the stakeholders, so that conflicting claims are not only explicitly considered but also balanced against each other in accordance with a hypothetical principle of agreement that the parties would have accepted ex ante when the firm was founded if all the information available now had been considered at that time. From the ethical point of view, because the solution proposed results from a process of hypothetical bargaining, it is neutral. It does not reflect any arbitrariness in the bargaining status quo, and it also fulfils two principles of distributive justice. For reasons of realism, it is chosen from among the institutionally feasible arrangements. That is to say, this is not a Utopian theory, but rather a theory constrained by the need to give a viable design to the economic institutions (and which for example envisages exclusive property rights in the form that we have seen). The structure of rights and duties is deduced and justified endogenously, from the simple idea of a rational agreement, not imposed on the basis of a mere intuition of what society as a whole would require of the firm. It does not suffer from the normative indeterminacy of other normative stakeholder theories.

\section{References}

Alchian A. and Demsetz H. (1972), "Production, Information costs and economic Organization", 62, Amer. Economic Review, pp.777-795.

Aoki M (1984), The Cooperative Game Theory of the Firm, Oxford U.P.

Barry B. (1989), Theories of Justice, London, Harvester-Wheatsheaf.

Binmore K. and P. Dasgupta (eds.) (1987), The economics of bargaining, Basil Blackwell, Oxford

Binmore K. (1989), "Social Contract I: Harsanyi and Rawls", The Economic Journal, 99, pp.84-102.

Binmore K.(1991), "Game Theory and The Social Contract", in R.Selten (ed.), Game Equilibrium Models in Economics, Ethics and Social Sciences, Berlin, Springer

Binmore K. (1994), Playing Fair, Cambridge Mass., MIT Press.

Binmore K. (1997), Just Playing, Cambridge Mass., MIT Press.

Blair M. (2002), Post Enron Reflections on Comparative Corporate Governance, Georgetown University Law Centre, Working paper series in Business, Economics and Regulatory law, , n. 316663 .

Blair M. and L. Stout (1999), “A Team Production Theory of Corporate Law”, Virginia Law Review, Vol. 85, No. 2.

Bowie M. (1999), Business Ethics: a Kantian Perspective, Oxford, Blackwell.

Brock H.W. (1978), "A New Theory of Social Justice Based on the Mathematical Theory of Games", in Ordeshook (ed.) Game Theory and Political Science, New York, New York University Press.

Brock H.W. (1979), "A Game Theoretical Account of Social Justice”, Theory and Decision, 11, pp. 239-265.

Buchanan J. (1975), The Limits of Liberty, The Univ. of Chicago Press.

Chapman B. (1993), "Trust, economic rationality and corporate fiduciary obligation", in "The Corporate Stakeholder Conference", University of Toronto Law Journal, XLII, n.3, pp. 547-588.

Daniels R. (1993), "Stakeholder and takeovers: can contractarianism be compassionate?" in "The Corporate Stakeholder Conference", University of 
Toronto Law Journal, XLII, n.3, pp. 315-352.

Dodd E.N. (1932), "For whom are corporate manager trustees?", Harvard Law Review, 45, pp.1145-1163.

Conry E.J. (1995), “A Critique of Social Contracts for Business", Business Ethics Quarterly, 5, 2, ,pp.187-212.

Donaldson T., T.W. Dunfee (1995), "Integrative Social Contracts Theory". Economics and Philosophy, 11, pp.85-112

Donaldson T., L. Preston (1995), "The stakeholder Theory of the Corporation: Concepts, Evidence, and Implications", Academy of Management Review, 20, 1, pp.65-91.

Donaldson T., T.W. Dunfee (1994), "Toward a unified conceptions of business ethics: integrative social contract theory", Academy of Management Review, 19, 2, pp. 252 - 284.

Donaldson T. and T.W. Dunfee, (1999), Ties that Bind; A Social Contract Approach to Business Ethics, Harvard Business School Press.

Englander E., A, Kaufman (2003), Managerial fiduciary duty and social responsibility: the Changing nature of corporate governance in the post-war America, SMPP working paper 03-04, George Washington University of Business and Public management.

European Commission, Green Paper: Promoting a European framework for Corporate Social Responsibility, (Bruxelles, 18/07/2001).

Flannigan R. (1989), "The Fiduciary Obligation", Oxford Journal of Legal Studies, 9, pp.285-294.Freeman E. (1984), Strategic Management, A Stakeholder Approach, Pitman, Boston.

Freeman E. and W.M.Evan (1989), "Stakeholder Management and the Modern Corporation: Kantian Capitalism", in Beauchamp and Bowie (eds.) Ethical Theory and Business, 3rd ed., Prentice Hall, Englewood Cliffs,N.J.

Freeman R.E. and J. McVea (2002), A stakeholder approach to Strategic management, Working paper n.01-02, Darden Graduate School of Business Administration.

Freeman T. and W.M. Evan (1990), "Corporate Governance: A Stakeholder Interpretation", The Journal of Behavioural Economics, 19, 4, pp.337-359

Gauthier D. (1986), Morals by Agreement, Oxford Clarendon Press.

Gauthier D. (1996), "Commitment and Choice: An Essay on the Rationality of Plans" in Ethics, Rationality, Economic Behaviour, F.Farina, S.Vannucci and F.Hahn eds., Oxford U.P. Oxford.

Gauthier D.(1990), "Economic Man and the Rational Reasoner", in J. Nichols and C.Wright (eds.) From Political Economy to Economics And Back?, San Francisco, ICS Press.

Green L. (1990), The Authority of the State, Oxford, Clarendon Press.

Grossman S. and Hart O. (1986), "The Costs and Benefit of Ownership: A Theory of Vertical and Lateral Integration" , Journal of Political Economy, 94, pp.691-719.

Hansmann H.(1988), "Ownership of the Firm", Journal of Law Economics and Organization, 4, 2, pp.263-304.

Hansmann H.. (1996), The ownership of enterprise, Harvard U.P., Cambridge Mass

Harsanyi J.C. (1977), Rational Behaviour and Bargaining Equilibrium in Games and Social Situations, Cambridge (Cambridge University Press). 
Hart O. (1993), “An economist's view of fiduciary view”, in The Corporate Stakeholder Conference, University of Toronto Law Journal, XLII, n.3, pp. 299-315

Hart O. (1995), Firms, Contract and Financial Structure, Oxford, Clarendon Press.

Hart O. and J.Moore (1990), "Property Rights and the Nature of the Firm", Journal of Political Economy, 98, pp.1119-1158.

Hendry, J.(2001), "Missing the Target: Normative Stakeholder Theory and the Corporate Governance Debate", Business Ethics Quarterly, 11, 1, pp. 159-176.

Jensen M.C. (2001), "Value Maximization, Stakeholder Theory, and the Corporate Objective Function" Journal of Applied Corporate Finance, Vol. 14, No 3, Fall.

Kalai E. and Smorodinsky M.(1975), "Other Solution to Nash's Bargaining Problem”, Econometrica, vol.43, 3,880-895.

Kaufman A. (2002), "Managers' Double Fiduciary Duty: To stakeholders and to Freedom", Business Ethics Quarterly, 12, 2, pp.189-213.

Kaufman A., E. Englander and C.H.Wood (2003), A team production model of corporate governance revisited, SMPP working paper 03-03, George Washington University of Business and Public Management.

Kreps, D, (1998), "Bounded Rationality", in The New Palgrave Dictionary of Economics and Law, London, McMillan.

McClennen E. (1990), "Foundational Exploration for a Normative Theory of Political Economy", Constitutional Political Economy, 1, pp.67-99.

McClennen E. (1993), "Rationality, Constitutions and the Ethics of Rules", Constitutional Political Economy, 4. pp.173-210.

McMahon C. (1989), "Managerial Authority", Ethics, October.

Nagel T. (1986), A view form nowhere, Oxford, Oxford University press.

Nash J. (1950), “The Bargaining Problem”, Econometrica, 18, pp.155-162.

OECD, Principles of Corporate Governance, April, 1999.

Phillips R., Freeman E., Wicks A.C. (2003), "What Stakeholder Theory is Not" Business Ethics quarterly, vol. 13, 4, pp. 479-502.

Raiffa H. (1953), “Arbitration Schemes for Generalized Two Person Games”, in Kuhn, Tucker (eds.) Contribution to the Theory of Games, Princeton U.P.,361-387.

Rajan R. and L.Zingales (2000),'The Governance of the New Enterprise", in Xavier Vives (ed.) Corporate Governance, Theoretical and Empirical Perspective, Cambridge , Cambridge UP.

Rajan R.and L. Zingales (1998), "Power in a theory of the firm", Quarterly Journal of Economics, CXIII, pp.387-432.

Rawls J. (1971), A Theory of Justice, Oxford, Oxford U.P..

Raz J. (1985), "Authority and Justification", Philosophy and Public Affairs, 1985, pp.3-

Romano R.A (1993), What is the value of other constituency statutes to stakeholders?, in "The Corporate Stakeholder Conference", University of Toronto Law Journal, XLII, n.3, pp. 533-544

Rubinstein A. (1987), "Bargaining Model with Incomplete Information about Time Preference", in Binmore K. e P. Dasgupta (eds.) The economics of bargaining, Oxford, Basil Blackwell.

Sacconi L. (1991), Etica degli affari, individui, imprese e mercati nella prospettiva dell'etica razionale, Milano, Il Saggiatore. 1995,

Sacconi L. (1999), "Codes of ethics as contractarian constraint on abuse of authority: a perspective from the theory of the firm", Journal of business ethics, 21, 
pp.189-202

Sacconi L. (2000), The Social Contract of the Firm. Economics, Ethics and Organisation, Springer Verlag, Berlin.

Sacconi L.(2004), CSR as a model of extended corporate governance, an explanation based on the economic theory of social contract, reputation and reciprocal conformism, Liuc paper n.142,

Sen A. (1970), Collective Choices and Social welfare, Holden Day, San Francisco, $2^{\text {nd }}$ ed. North Holland, 1979

Shapley L.S. (1953), "A value for N-Person Games", in Kuhn and Tucker (eds.), Contributions to the Theory of Games, Princeton U.P. pp.307-317.

Sternberg E.(2001), The stakeholder concept: a mistaken doctrine, Centre for business and professional ethics and Foundation for Business Responsibility.

Tirole J. (2001), "Corporate Governance", Econometrica, vol. 69, n. 1, pp. 1-35

Vanberg V.J. (1992), "Organizations as Constitutional Order", Constitutional Political Economy, vol.3,n.2, pp.223-255.

Willamson O.(1986), The Economic Institutions of Capitalism, New York, The Free Press.

Williamson O. (1975), Market and Hierarchies, New York, The Free Press.

Zingales L. (1998), " Corporate governance" Palgrave Dictionary of economics and the Law, London, McMillan. pp.497-503 
Elenco dei papers del Dipartimento di Economia

2000.1 A two-sector model of the effects of wage compression on unemployment and industry distribution of employment, by Luigi Bonatti

2000.2 From Kuwait to Kosovo: What have we learned? Reflections on globalization and peace, by Roberto Tamborini

2000.3 Metodo e valutazione in economia. Dall'apriorismo a Friedman, by Matteo Motterlini

2000.4 Under tertiarisation and unemployment. by Maurizio Pugno

2001.1 Growth and Monetary Rules in a Model with Competitive Labor Markets, by Luigi Bonatti.

2001.2 Profit Versus Non-Profit Firms in the Service Sector: an Analysis of the Employment and Welfare Implications, by Luigi Bonatti, Carlo Borzaga and Luigi Mittone.

2001.3 Statistical Economic Approach to Mixed Stock-Flows Dynamic Models in Macroeconomics, by Bernardo Maggi and Giuseppe Espa.

2001.4 The monetary transmission mechanism in Italy: The credit channel and a missing ring, by Riccardo Fiorentini and Roberto Tamborini.

2001.5 Vat evasion: an experimental approach, by Luigi Mittone

2001.6 Decomposability and Modularity of Economic Interactions, by Luigi Marengo, Corrado Pasquali and Marco Valente.

2001.7 Unbalanced Growth and Women's Homework, by Maurizio Pugno

2002.1 The Underground Economy and the Underdevelopment Trap, by Maria Rosaria Carillo and Maurizio Pugno.

2002.2 Interregional Income Redistribution and Convergence in a Model with Perfect Capital Mobility and Unionized Labor Markets, by Luigi Bonatti.

2002.3 Firms' bankruptcy and turnover in a macroeconomy, by Marco Bee, Giuseppe Espa and Roberto Tamborini.

2002.4 One "monetary giant" with many "fiscal dwarfs": the efficiency of macroeconomic stabilization policies in the European Monetary Union, by Roberto Tamborini.

2002.5 The Boom that never was? Latin American Loans in London 1822-1825, by Giorgio Fodor. 
2002.6 L'economia senza banditore di Axel Leijonhufoud: le 'forze oscure del tempo e dell'ignoranza' e la complessità del coordinamento, by Elisabetta De Antoni.

2002.7 Why is Trade between the European Union and the Transition Economies Vertical?, by Hubert Gabrisch and Maria Luigia Segnana.

2003.1 The service paradox and endogenous economic gorwth, by Maurizio Pugno.

2003.2 Mappe di probabilità di sito archeologico: un passo avanti, di Giuseppe Espa, Roberto Benedetti, Anna De Meo e Salvatore Espa.

(Probability maps of archaeological site location: one step beyond, by Giuseppe Espa, Roberto Benedetti, Anna De Meo and Salvatore Espa).

2003.3 The Long Swings in Economic Understianding, by Axel Leijonhufvud.

2003.4 Dinamica strutturale e occupazione nei servizi, di Giulia Felice.

2003.5 The Desirable Organizational Structure for Evolutionary Firms in Static Landscapes, by Nicolás Garrido.

2003.6 The Financial Markets and Wealth Effects on Consumption An Experimental Analysis, by Matteo Ploner.

2003.7 Essays on Computable Economics, Methodology and the Philosophy of Science, by Kumaraswamy Velupillai.

2003.8 Economics and the Complexity Vision: Chimerical Partners or Elysian Adventurers?, by Kumaraswamy Velupillai.

2003.9 Contratto d'area cooperativo contro il rischio sistemico di produzione in agricoltura, di Luciano Pilati e Vasco Boatto.

2003.10 Il contratto della docenza universitaria. Un problema multi-tasking, di Roberto Tamborini.

2004.1 Razionalità e motivazioni affettive: nuove idee dalla neurobiologia e psichiatria per la teoria economica? di Maurizio Pugno.

(Rationality and affective motivations: new ideas from neurobiology and psychiatry for economic theory? by Maurizio Pugno.

2004.2 The economic consequences of Mr. G. W. Bush's foreign policy. Can th US afford it? by Roberto Tamborini

2004.3 Fighting Poverty as a Worldwide Goal by Rubens Ricupero

2004.4 Commodity Prices and Debt Sustainability by Christopher L. Gilbert and Alexandra Tabova

2004.5 A Primer on the Tools and Concepts of Computable Economics by K. Vela Velupillai 
2004.6 The Unreasonable Ineffectiveness of Mathematics in Economics by Vela K. Velupillai

2004.7 Hicksian Visions and Vignettes on (Non Linear) Trade Cucle Theories by Vela K. Velupillai.

2004.8 Trade, inequality and pro-poor growth: Two perspectives, one message? by Gabriella Berloffa and Maria Luigia Segnana.

2004.9 Worker involvement in entrepreneurial nonprofit organizations. Toward a new assessment of workers? Perceived satisfaction and fairness by Carlo Borzaga and Ermanno Tortia.

2004.10 A Social Contract Account for CSR as Extended Model of Corporate Governance (Part I): Rational Bargaining and Justification by Lorenzo Sacconi 

PUBBLICAZIONE REGISTRATA PRESSO IL TRIBUNALE DI TRENTO 